\title{
Recent advances on organocatalysed asymmetric Mannich reactions
}

\author{
Xiao-hua Cai* and Bing Xie \\ College of Chemistry and Environmental Science, Guizhou Minzu University, Guiyang 550025, \\ P. R. China \\ E-mail: caixh1111@163.com
}

DOI: http://dx.doi.org/10.3998/ark.5550190.p007.839

\begin{abstract}
The asymmetric Mannich reaction is one of the most useful carbon-carbon bond forming reactions for the synthesis of chiral molecules containing nitrogen. The resulting $\beta$-amino carbonyl compounds are valuable synthons in the preparation of many natural products with useful biological properties. This review provides an overview of asymmetric Mannich reactions in recent years under different organocatalytic systems, including: chiral amines, chiral bifunctional thiourea, chiral Brønsted acids and other chiral organocatalytic systems.
\end{abstract}

Keywords: Asymmetric Mannich reaction, organocatalysis, enantioselective, diastereoselectivity

\section{Table of Contents}

1. Catalysed by Chiral Amines

1.1 L-Proline and its derivatives

1.2 Pyrrolidine derivatives

1.3 Cinchona alkaloids or theirs derivatives

1.4 Other chiral amines

2. Catalysed by Chiral Bifunctional Thioureas

3. Catalysed by Chiral Brønsted Acids

4. Catalysed by Other Chiral Organocatalytic Systems

\section{Introduction}

The asymmetric Mannich reaction ${ }^{1-7}$ is one of the most powerful carbon-carbon bond-forming reactions for the construction of nitrogen-containing compounds. The utilization of this reaction allows for the preparation of optically enriched $\beta$-amino carbonyl compounds and their 
derivatives. In some instances these reactions have proven effective for the generation of biologically significant and synthetically useful $\beta$-amino acids that contain a quaternary stereocenter substituted with a nitrogen atom adjacent to the carbonyl group. ${ }^{8-10}$ Traditionally, asymmetric Mannich reactions are catalyzed by chiral transition-metal complexes. ${ }^{11-17}$ In 2000 , List described firstly the $L$-proline catalysed Mannich reaction. ${ }^{18-19}$ This landmark discovery stimulated the rapid development of many asymmetric organocatalytic Mannich reactions. The typical organocatalytic approach to asymmetric Mannich reaction is based on enamine activation of carbonyl compounds using secondary amine organocatalysts. ${ }^{20}$ Other types of organocatalysts have also been successfully used for Mannich-type reactions. This review provides an overview of asymmetric Mannich reactions covering from 2007 to now under different organocatalytic systems in recent years. Several organocatalytic approaches will be reviewed, which can be divided in catalysis by (i) chiral amines, (ii) chiral bifunctional thioureas (iii) chiral Brønsted acids, and (iv) other chiral organocatalysis.

\section{Catalysed by Chiral Amines}

Organocatalytic Mannich reactions can be carried out either as three-component, one-pot reactions or as reactions of preformed imines with aldol donors. Chiral amines resulting in chiral enamines can attack a Mannich acceptor, usually a prochiral aldimine, thereby introducing one or two stereocenters in the Mannich product. The catalytic cycle is completed by regeneration of the amine catalyst through hydrolysis. The products are $\beta$-aminoaldehydes or $\beta$-aminoketones, which are optionally substituted at the $\alpha$-position..$^{5}$

\subsection{L-Proline and its derivatives}

Among a wide variety of organocatalysts that have been used in the asymmetric Mannich reaction, the most widely used is proline. L-proline-catalysed Mannich reactions gives easy access to syn-products. Mechanistically, the stereochemical outcome of all of the reactions can be explained by invoking a transition state as depicted in Scheme 1. The stereochemical repulsion between the PMP-group and the proline moiety, in combination with protonation of the imine by the acid-functionality of proline, accounts for a si-face attack of the (E)-aldimine (from $p$-anisidine and acceptor aldehyde) by the si-face of the (E)-enamine formed by the ketone and proline. ${ }^{21}$ This model explains the stereochemical outcome of many similar reactions that have appeared in literature.

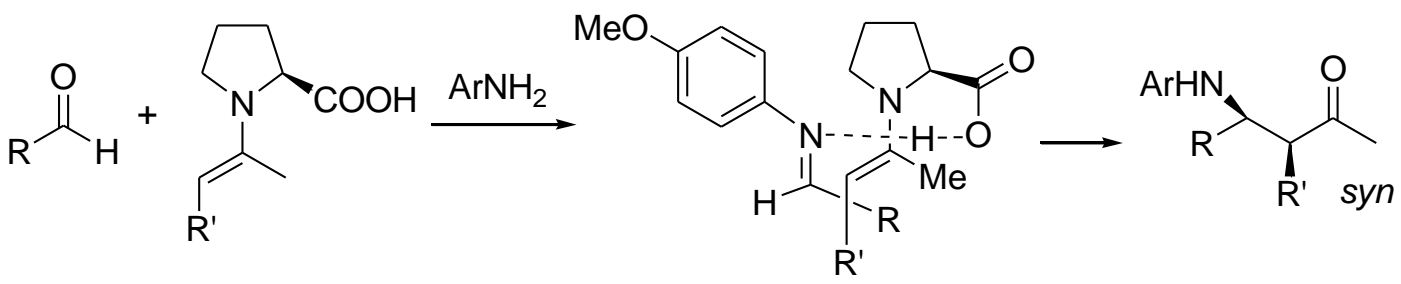




\section{Scheme 1}

In 2008, $\mathrm{Xu}$ and coworkers ${ }^{22}$ reported an enantioselective synthetic method for substituted tetrahydropyridines via a proline-mediated cascade Mannich-type/intramolecular cyclization (Scheme 2). The advantage of the organocatalyst was that the Mannich-type reaction proceeded efficiently with excellent diastereo- and enantioselectivity in the presence of water. This strategy would easily provide access to structurally diverse N-PMP piperidines. In the same year, Glorius et al. ${ }^{23}$ developed the proline-catalyzed Mannich reaction of unactivated ketones, and demonstrated that the use of cyclic acceptors enabled the highly stereoselective synthesis of chiral 3-substituted morpholin-2-ones (Scheme 3). These products corresponded to $\alpha$ - $D$-amino acids that were protected at the $\mathrm{N}$ and $\mathrm{O}$ terminus by the diphenylethylene group. This protecting group for $\alpha$-amino acids could be cleaved readily by hydrogenolysis in aqueous ethanol to furnish the free amino acid.

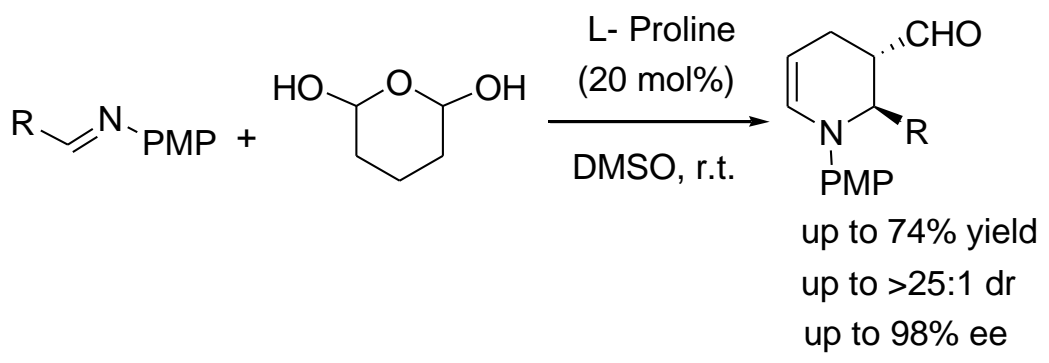

\section{Scheme 2}

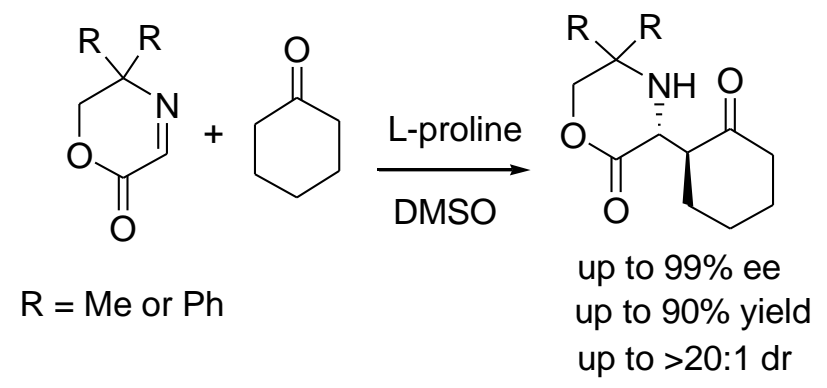

\section{Scheme 3}

List $^{19}$ introduced the one-pot catalytic asymmetric synthesis of pseudo- $\mathrm{C}_{2}-$ symmetric $\beta, \beta$ '-diaminoaldehydes with extremely high stereoselectivities, starting from acetaldehyde and either aromatic or aliphatic N-Boc imines (Scheme 4). The method was effectively extended to cross-Mannich reactions, furnishing $\beta, \beta$ '-diamino aldehydes containing three adjacent stereogenic centers. 


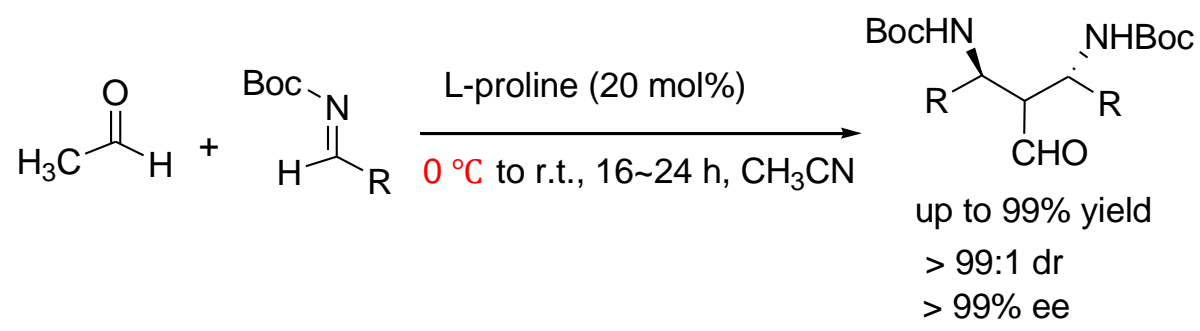

\section{Scheme 4}

In 2010, Zhao and coworkers ${ }^{24}$ reported the one-pot organocatalytic reactions between $\alpha$ amido sulfones and unmodified aldehydes proceeded with high chemo- and enantioselectivities to furnish $\beta$-amino aldehydes in high yields with up to $95: 5 \mathrm{dr}$ and up to $99 \%$ ee (Scheme 5). In the same year, $\mathrm{Li}$ et $a l .{ }^{25}$ developed that 2-Aryl-3H-indol-3-ones reacted with aldehydes or ketones to afford the corresponding aza-quaternary carbon addition product in good yield with moderate to excellent regioselectivity and enantioselectivity, showed $L$-proline was an effective catalyst in the reaction. The system was applied to the reaction of 2-(2-bromo-phenyl)-3H-indol3-one and acetaldehyde to produce 2-[2-(2-bromophenyl)-3-oxoindolin-2-yl] acetaldehyde, which was a precursor for the synthesis of some alkaloids such as hinckdentine A (Scheme 6).

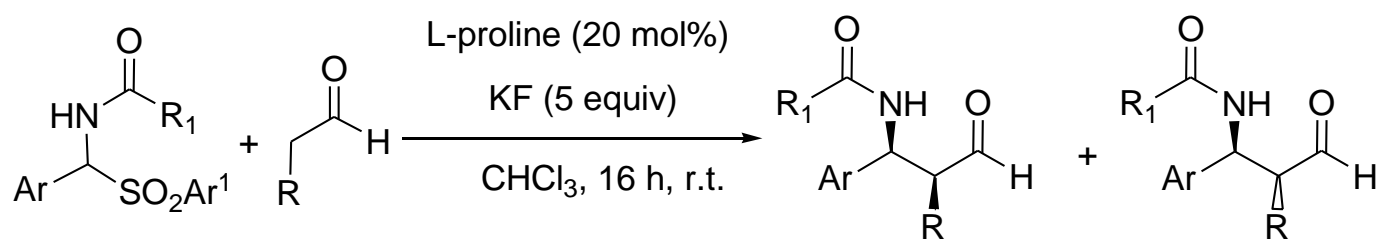

\section{Scheme 5}

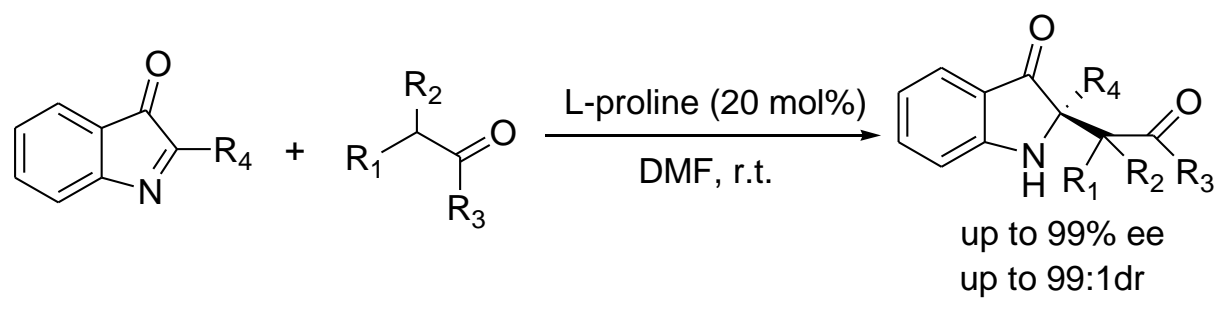

\section{Scheme 6}

In 2009, Carter and Yang ${ }^{26}$ developed an organocatalyzed method for accessing nitrogencontaining [2.2.2]-bicyclic scaffolds in a highly enantioselective and diastereoselective manner (Scheme 7). The $p$-dodecylphenylsulfonamide catalyst (1) allowed for the scope of this formal aza-Diels-Alder process to be expanded to include aryl imines. Additionally, alkyl imines proceeded with a divergent and novel reaction pathway, further demonstrating the utility of this technology. Next year, Sebesta $e t a l .{ }^{27}$ showed $L$-proline-derived sulfonamides (2) was effective 
catalysts in the Mannich reaction of cyclohexanone with N-PMP-protected $\alpha$-imino ethylglyoxylate with practical advantages in comparison with $L$-proline in different solvents and ionic liquids (Scheme 8). Ionic liquids could be used as solvents as well, although in this case, proline sulfonamides were less diastereo- and enantioselective than common organic solvents. Owing to larger differences in ionic liquids than in molecular solvents, a broader range of ionic liquids seemed to be necessary to gain deeper insight into the reactivity of these catalysts in the Mannich reaction.

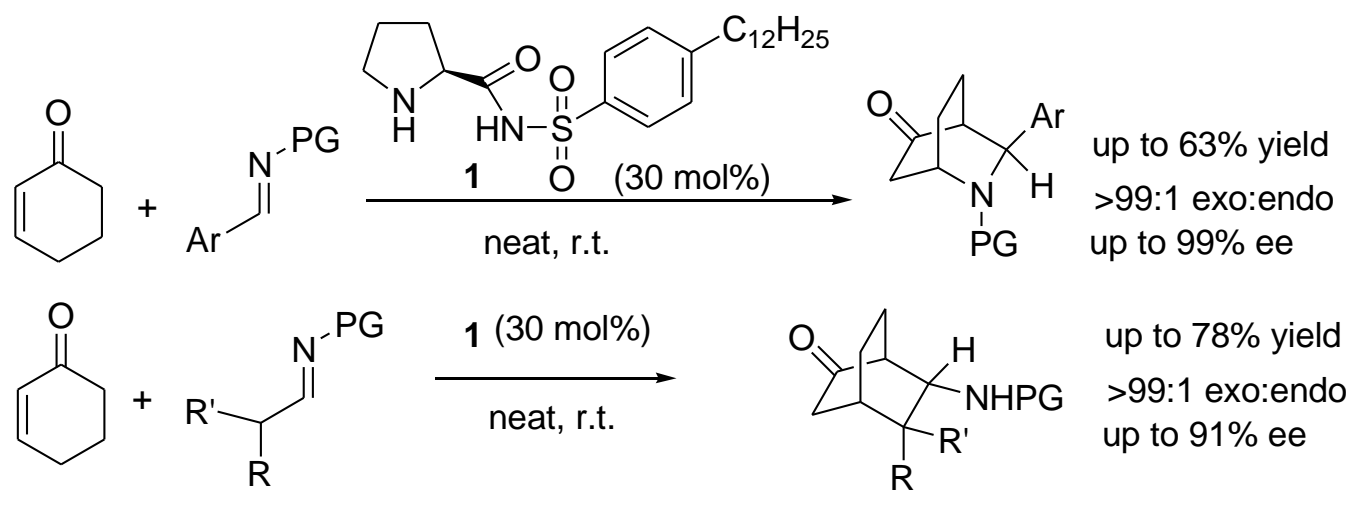

\section{Scheme 7}

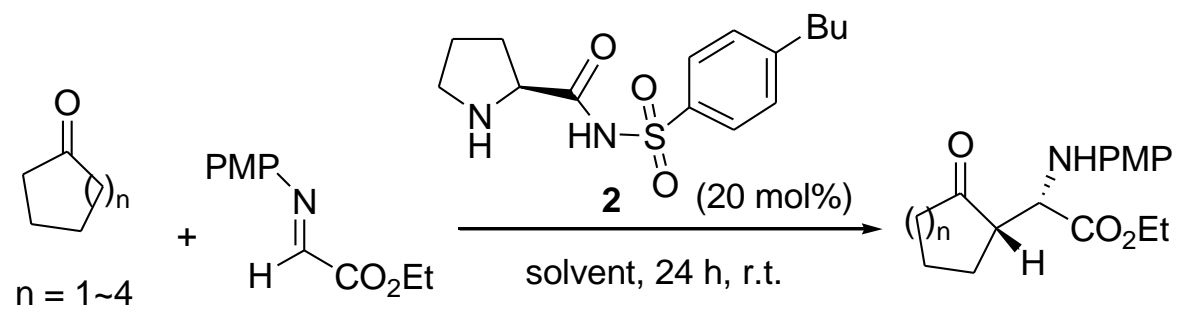

\section{Scheme 8}

In 2011, Lu et al. ${ }^{28}$ found the direct Mannich protocol with highly enantioselectivity employing fluoroacetone, $p$-anisidine, and aldehydes catalyzed by 4-siloxyproline (3), the approach allowed efficient access for pharmaceutically important fluorinated $\beta$-amino ketones (Scheme 9). Recently, An et al..$^{29}$ developed the asymmetric three-component Mannich reactions of cyclohexanone and anilines with aromatic aldehydes in the presence of $\mathrm{H}_{2} \mathrm{O}$ mediated by Isosteviol-proline (4) as highly efficient amphiphilic organocatalysts, and afforded syn-Mannich products with excellent diastereoselectivities (syn/anti up to 98 :2) and enantioselectivities (up to $>99 \%$ ee) (Scheme 10). 


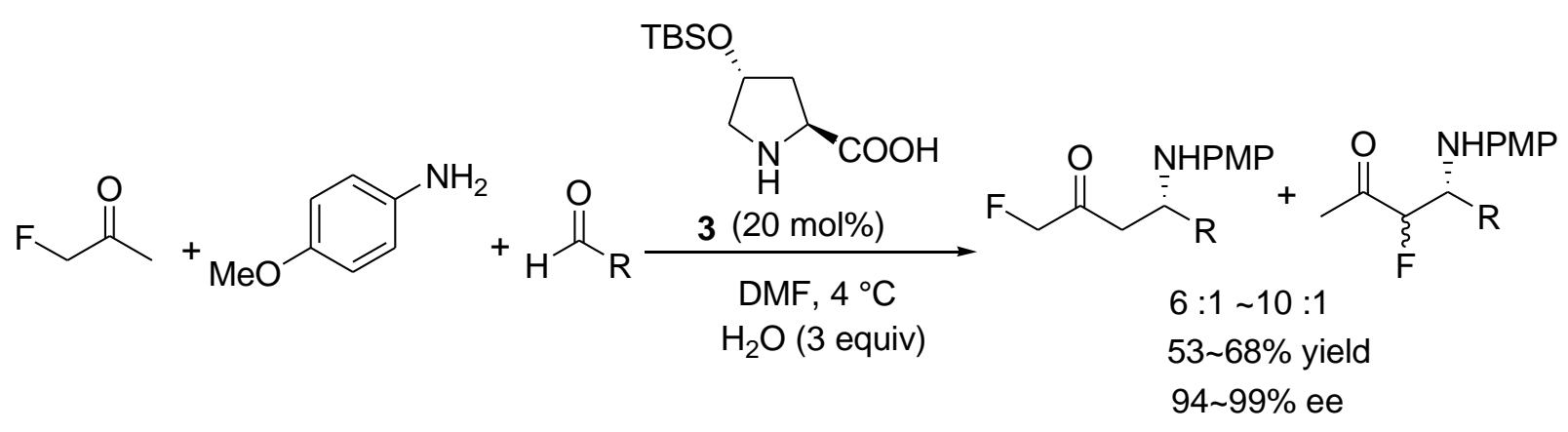

\section{Scheme 9}

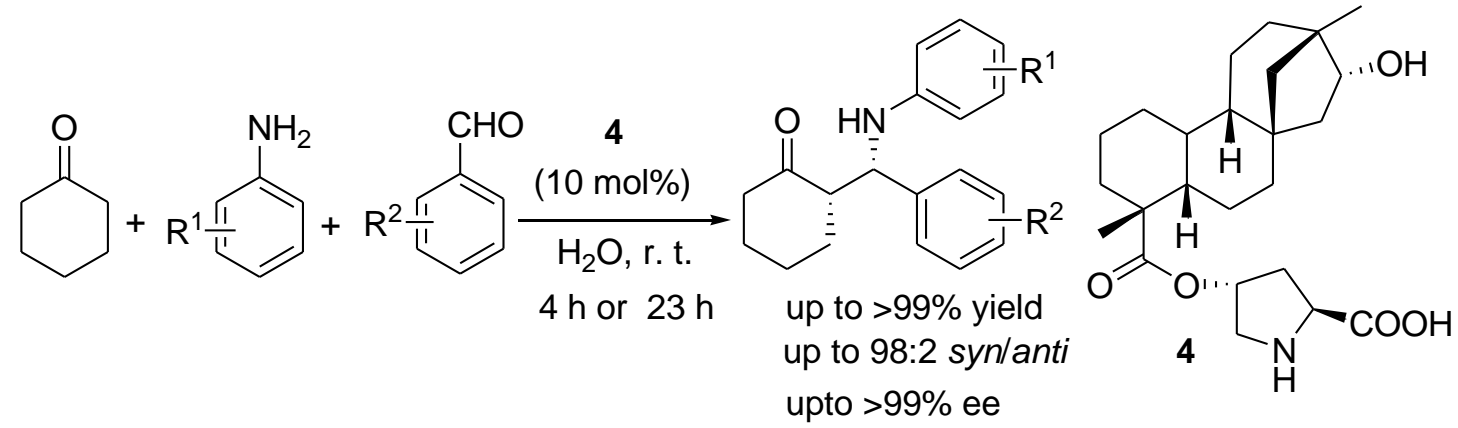

\section{Scheme 10}

\subsection{Pyrrolidine derivatives}

Nowadays, a series of enamine forming amines are available that give rise to the anti-products in good selectivity. The stereoselectivity observed when catalysts are used can be rationalized through the proposed transition state in the well-established enamine catalysis mechanism (Scheme 11). ${ }^{30}$ Thus, nucleophilic attack on the imine preferentially occurs from the (Si,Si) $l k$ face to afford the corresponding anti- $\beta$-amino aldehydes as major products. The asymmetric induction caused by the bulky pyrrolidine substituent is the opposite of that induced by hydrogen-bonding when proline is used as catalyst.

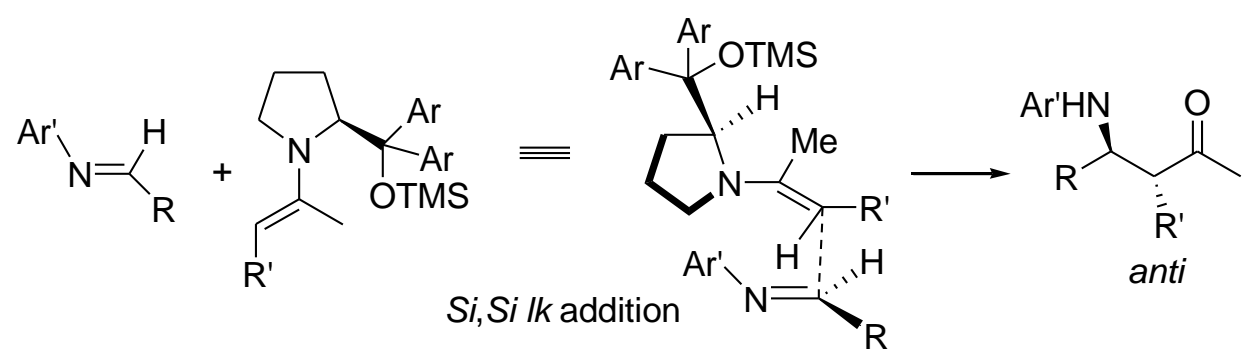

\section{Scheme 11}


In 2008, Melchiorre group ${ }^{31}$ discribed the the Hayashi-Jørgensen catalyst (5) catalyzed antiselective Mannich reaction of aldehydes with N-Cbz- and N-Boc-protected imines generated in situ from stable amido sulfones (Scheme 12). Besides the high level of efficiency and stereocontrol achieved, this approach introduced important synthetic advantages by avoiding the requirement to preform the $N$-carbamoyl imines. The following year, Fustero et al $^{32}$ reported that $\alpha, \alpha$-diarylprolinol trimethylsilyl ether (5 or $\mathbf{6})$ catalyzed the asymmetric Mannich reaction between fluoroalkyl aldimines and aldehydes. The corresponding Mannich adducts were reduced and afforded anti- $\beta$-alkyl- $\gamma$-fluoroalkyl- $\gamma$-amino alcohols in highly diastereo- and enantioselectivities (Scheme 13).

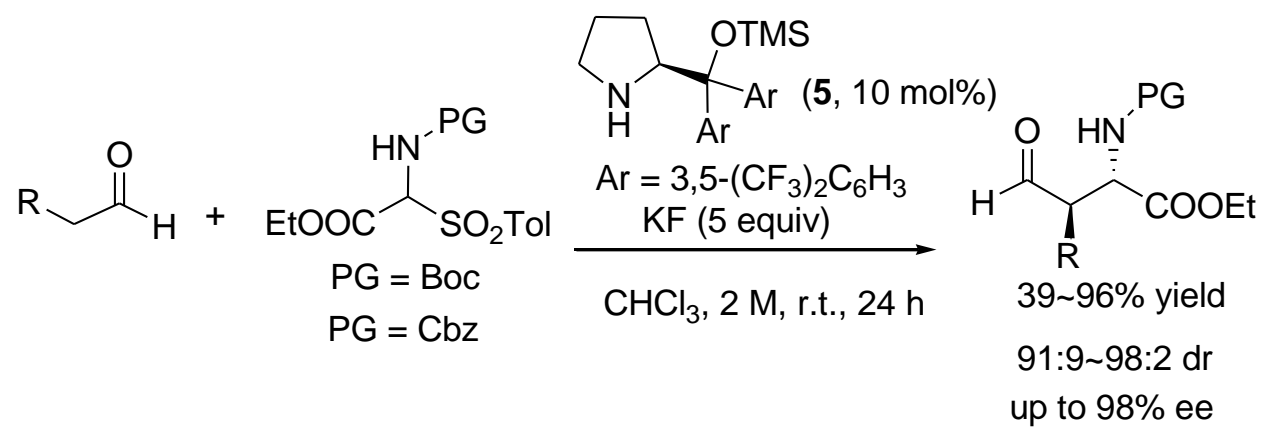

\section{Scheme 12}

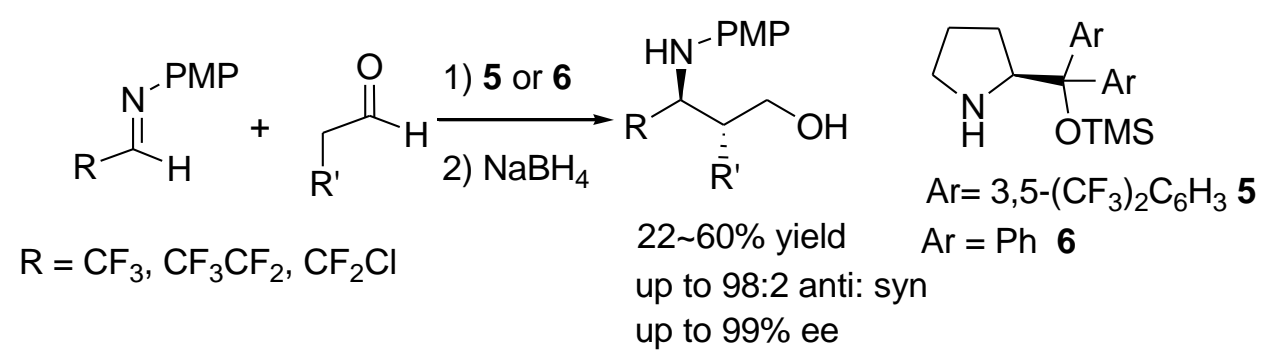

\section{Scheme 13}

Melchiorre et al $^{33}$ developed a highly efficient system for the asymmetric amino catalytic Mannich reaction of unmodified aldehydes with in situ generated N-carbamoyl imines in 2010, (Scheme 14). The main feature of this method lay in the operational simplicity: the highly reactive $\mathrm{N}$-carbamate-protected imines were generated in situ from stable, easily handled $\alpha$ amido sulfones. The judicious selection of commercially available chiral amine catalysts $\mathbf{6}$ and 7 allowed full control of the stereochemistry of the Mannich process; either the syn- or anti- $\beta$ amino aldehydes were accessible with very high stereocontrol. In 2011, Hayashi group ${ }^{34}$ also showed a highly diastereo- and enantioselectives asymmetric Mannich reaction of imines derived from aliphatic and aromatic aldehydes catalyzed by diarylprolinol silyl ether 5 (Scheme 15). Later, They still developed a one-pot synthesis of chiral aziridine derivatives with excellent 
diastereo- and enantioselectivities through uninterrupted sequential reactions, including desulfonylative formation of the N-Ts imine derived from chloroacetaldehyde, a diarylprolinol silyl ether mediated asymmetric Mannich reaction, reduction, and aziridine formation (Scheme 16). ${ }^{35}$ Because the generated product possesses several functional groups, with excellent diastereoselectivity and enantioselectivity and the synthetic procedure is simple, this method offers an efficient route for the preparation of chiral aziridine derivatives.

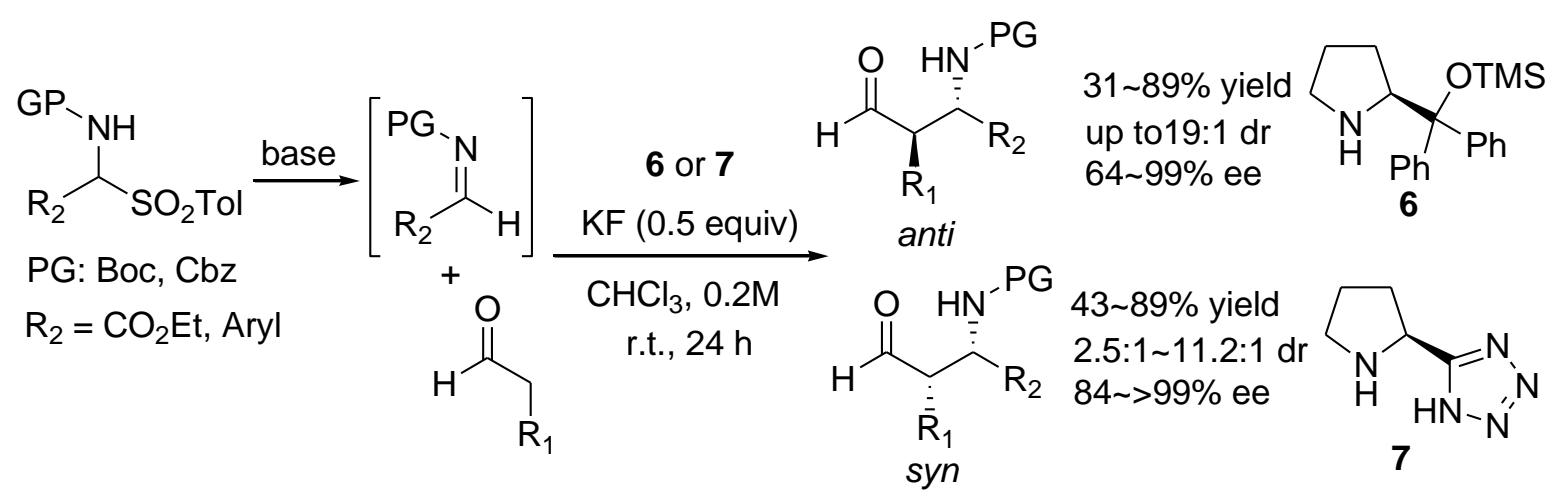

\section{Scheme 14}

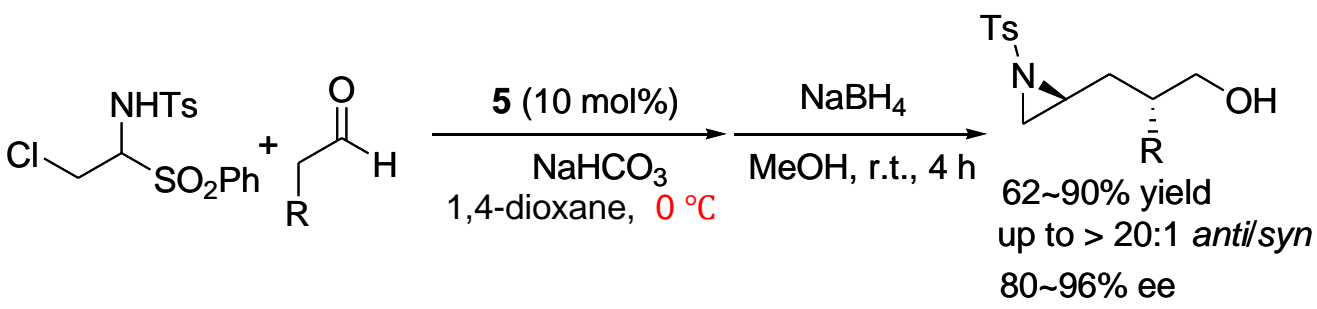

\section{Scheme 15}

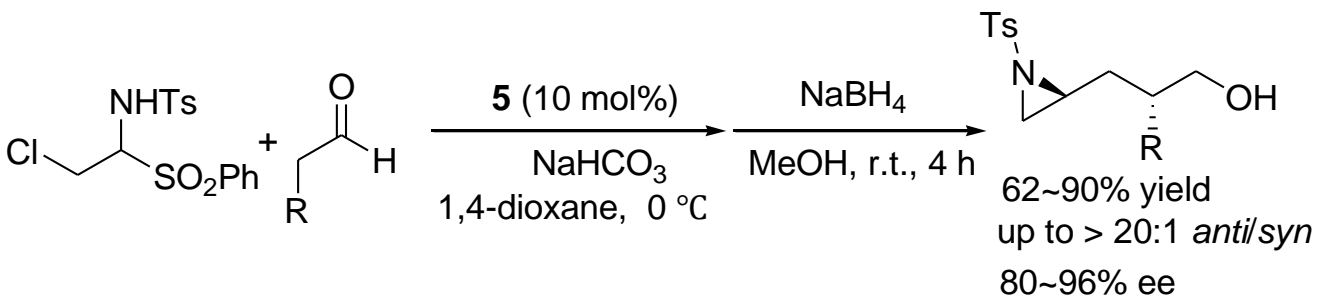

\section{Scheme 16}

In 2010, Palomo group ${ }^{36}$ reported an anti-selective Mannich reaction of aldehydes with Nsulfonyl imines had been developed by using a 4-hydroxypyrrolidine in combination with an external Brønsted acid (Scheme 17). This catalyst system combined an amino group to activate the aldehyde donor substrate, and a hydroxy group together with an external Bronsted acid to 
activate the imine acceptor component, while controlling the stereochemistry of the process. The Mannich adducts could be easily reduced or oxidized and then deprotected to give the corresponding $\beta$-amino acids and $\beta$-amino alcohols with good yields. The reaction results also showed that this ternary catalytic system was practical in other enamine-based reactions. In 2012, The group $^{37}$ still reported anti-selective and highly enantioselective Mannich reaction of aldehydes and unactivated imines mediated by the combined use of a Brønsted acid with an $\alpha, \alpha-$ dialkylprolinol ether catalyst (9) with good yields (typically 70 75\%), anti : syn ratios greater than $90: 10$, and ee values usually above 95\% (Scheme 18). The method worked particularly well with propargylic imines and, unlike previous catalytic routes to optically active propargylamines, provided adducts featuring two contiguous stereocenters and a functionalized side chain amenable for ulterior synthetic applications.

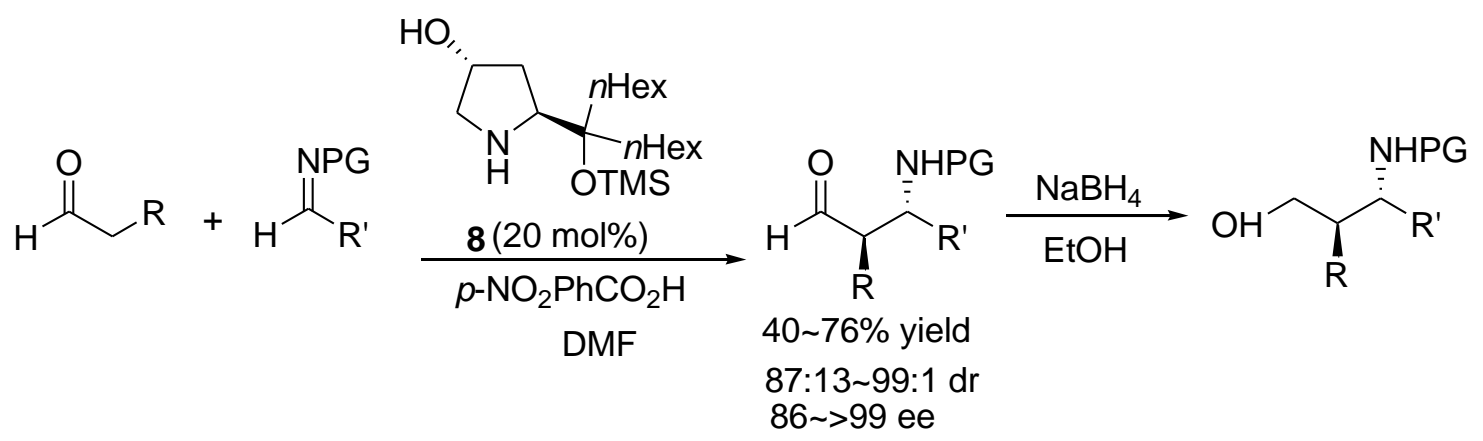

Scheme 17

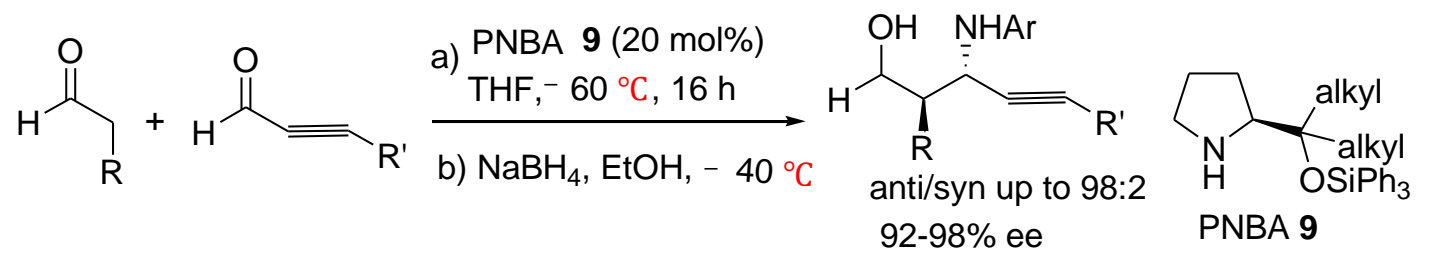

\section{Scheme 18}

Blanchet and coworkers ${ }^{38}$ reported an anti-selective direct and three-component Mannich reaction catalysed by 3-trifluoromethanesulfonamido-pyrrolidine (10) which achieved high yields and selectivities for various substrates ranging from linear and branched aldehydes to ketones (Scheme 19). The research disclosed that the acidity of the trifluoromethylsulfonamide group was critical to achieve high stereoselectivity, and C-2 symmetry of catalyst was not a key structural feature for a high stereoselectivity. Similar work for the enantioselective anti-selective Mannich-type reactions of aldehydes and ketones with imines catalyzed by 3pyrrolidinecarboxylic acid and related pyrrolidine derivatives was also reported by Tanaka at $a l .{ }^{39}$ in 2008. Hayashi group ${ }^{40}$ developed an asymmetric Mannich reaction mediated by the 
siloxytetrazole hybrid organocatalyst (11) in the presence of water without using organic solvents (Scheme 20).

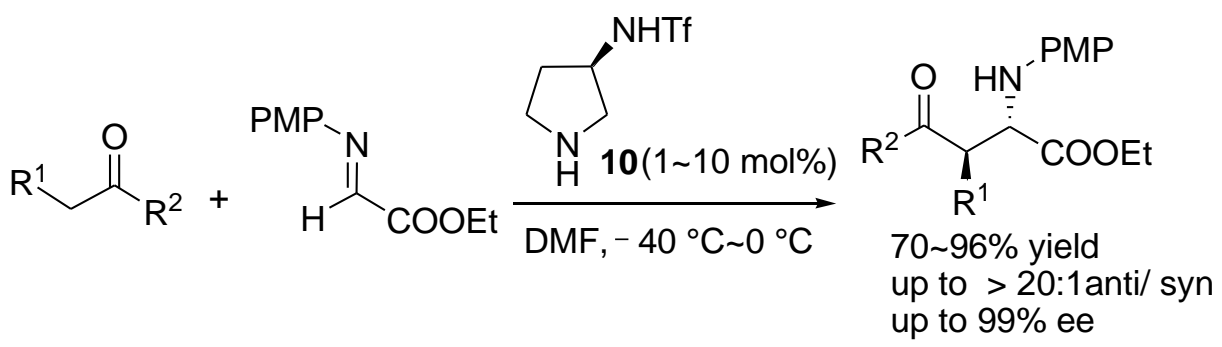

\section{Scheme 19}

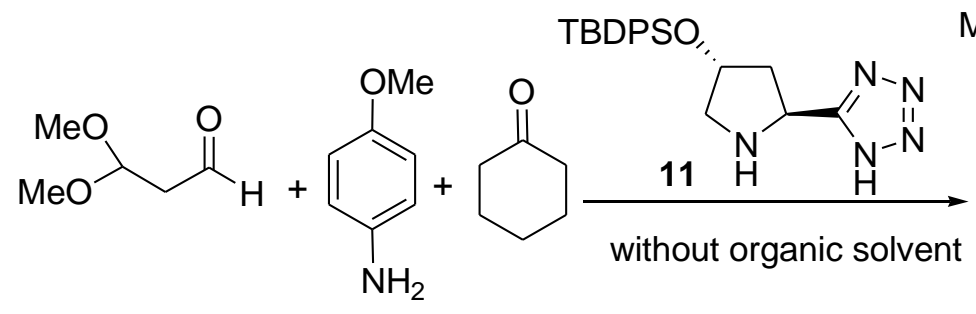<smiles>COc1ccc(NC(C(OC)OC)[C@H]2CCCCC2=O)cc1</smiles>

$95 \%$ ee

\section{Scheme 20}

\subsection{Cinchona alkaloids or theirs derivatives}

Schaus et al. $^{41}$ were first to describe the cinchona alkaloid-catalyzed Mannich reaction of dicarbonyl compounds with $\alpha$-amido sulfones as acyl imine precursors in good yields and high enantioselectivities, and in diastereoselectivities that range from 1:1 to > 95:5 (Scheme 21). The reaction required $10 \mathrm{~mol} \%$ of the cinchona alkaloid catalyst (12), which served as a general base to generate acyl imines in situ, and aqueous $\mathrm{Na}_{2} \mathrm{CO}_{3}$ to maintain the concentration of free alkaloid catalyst. The cinchonine catalyzed reactions gave practical access to highly functionalized building blocks which had been employed in the synthesis of chiral dihydropyrimidones, a class of compounds rich in diverse biological activity.

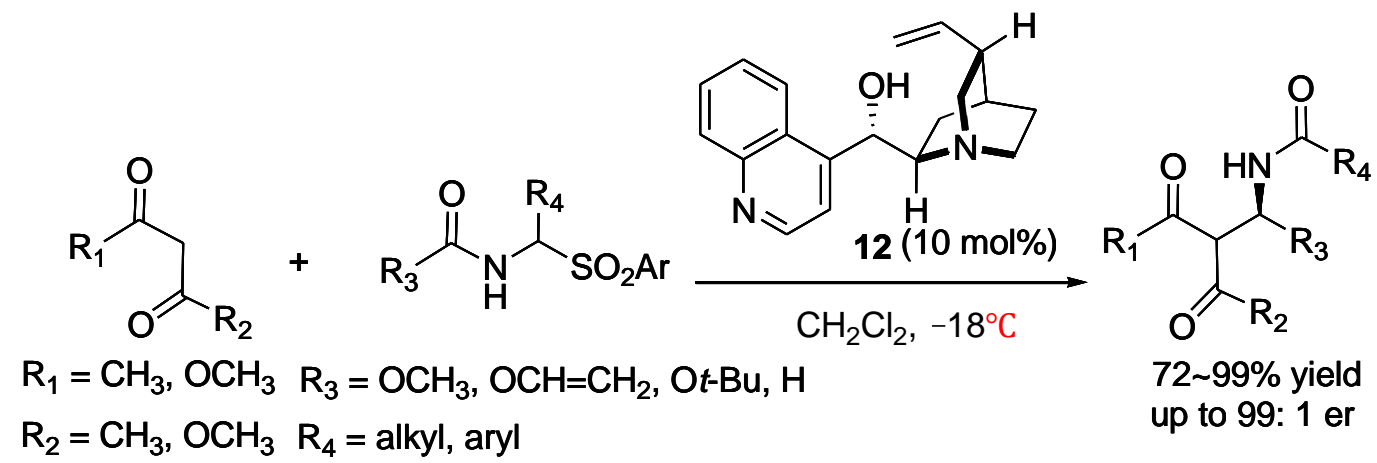

\section{Scheme 21}


Last year, Wang et al. ${ }^{42}$ showed the aza-Mannich addition of 2-(ethylthio)- thiazolones and $N$-tosyl aldimines were catalysed by cinchona alkaloid catalyst system (13) (Scheme 22). A series of masked chiral 2-(ethylthio)-thiazolone derivatives by establishing a carbon- and nitrogen-substituted quaternary carbon stereocenter, were synthesized with high levels of diastereo- (up to >98:2) and enantioselectivities (up to >99\%). Several new potential anticancer active derivatives were obtained.

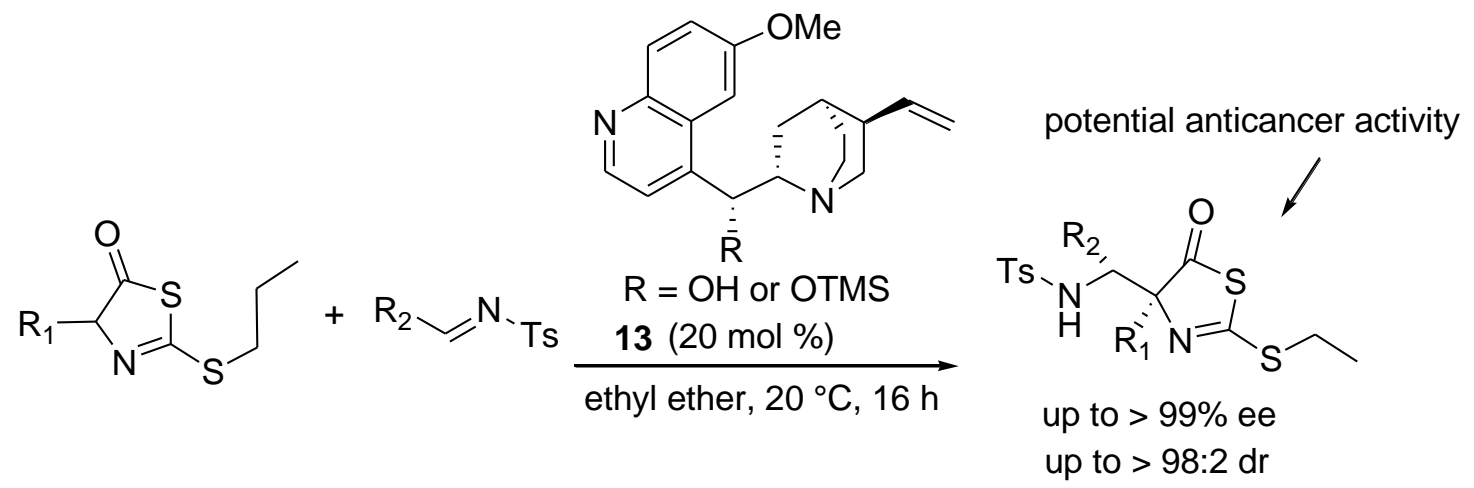

\section{Scheme 22}

Shibata and Toru et al. ${ }^{43}$ described the catalytic enantioselective fluorobisphenylsulfonyl methylation of in situ generated imines from $\alpha$-amido sulfones under the combination of Mannich type conditions with fluorobis(phenylsulfonyl)methane chemistry (Scheme 23). The $\alpha$ fluorobisphenylsulfonylmethylated amines could be converted to $\alpha$-mono- fluoromethyl amines by reductive desulfonylation.
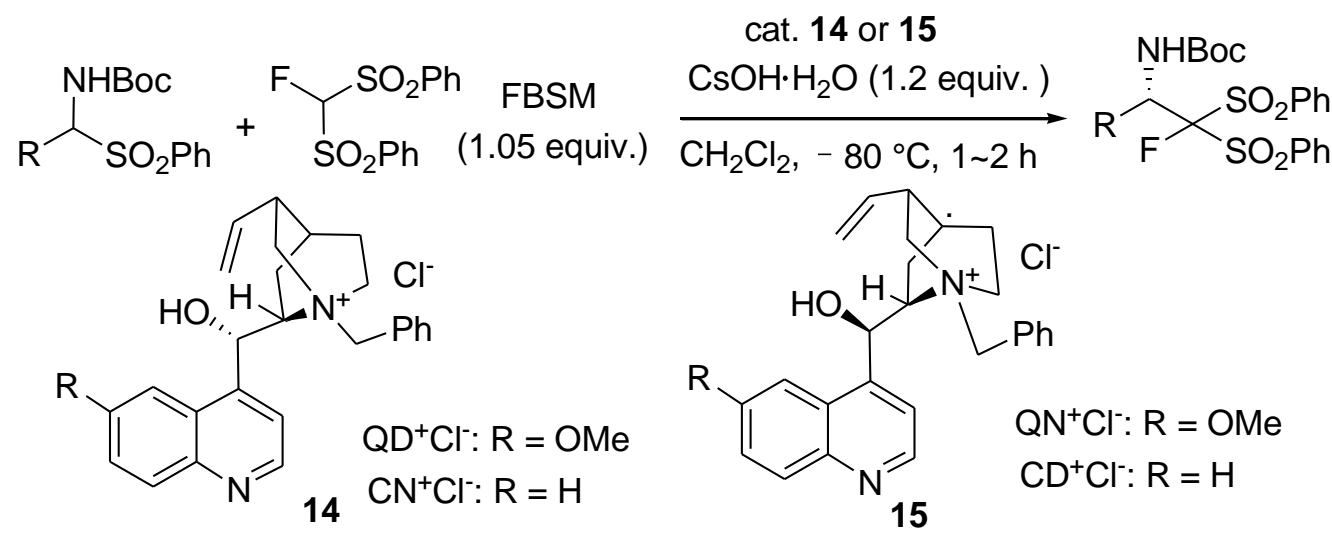

\section{Scheme 23}

\subsection{Other chiral amines}

In 2009, the Maruoka group ${ }^{44}$ developed a highly anti- and enantioselective direct asymmetric Mannich reaction catalysed by axially chiral amino sulfonamide (16) (Scheme 24). For instance, 
in the presence of a catalytic amount of 16, the reactions between aldehydes and $\alpha$-imino esters proceeded smoothly to produce a higher anti/syn ratio as well as higher enantioselectivity Mannich products than previously possible for Mannich products. The axially chiral amino sulfonamide 16 was also successfully applied to asymmetric direct cross-aldol reaction between two different aldehydes. The advantage of catalyst 16 was giving mainly syn products, whereas proline showed the opposite anti selectivity. The same year, they still reported that a highly stereoselective direct asymmetric Mannich reaction between acetaldehyde and $N$-Boc-protected imines, as well as an anti-selective direct asymmetric Mannich reaction of $N$-Boc-protected imines by using the less nucleophilic chiral amino sulfonamide $\mathbf{1 6}$ to suppress the undesired side reactions. ${ }^{45}$ Recently, this group ${ }^{46}$ introduced both syn- and anti-selective asymmetric direct Mannich reactions of N-protected aminoacetaldehydes with N-Boc-protected imines catalyzed by proline and the axially chiral amino sulfonamide 16 (Scheme 25). This organocatalytic process represented the first example of a Mannich reaction using Z- or Boc-protected aminoacetaldehyde as a new entry of $\alpha$-nitrogen functionalized aldehyde nucleophile in enamine catalysis. The obtained optically active vicinal diamines were useful chiral synthons as exemplified by the formal synthesis of (-)-agelastatin A.

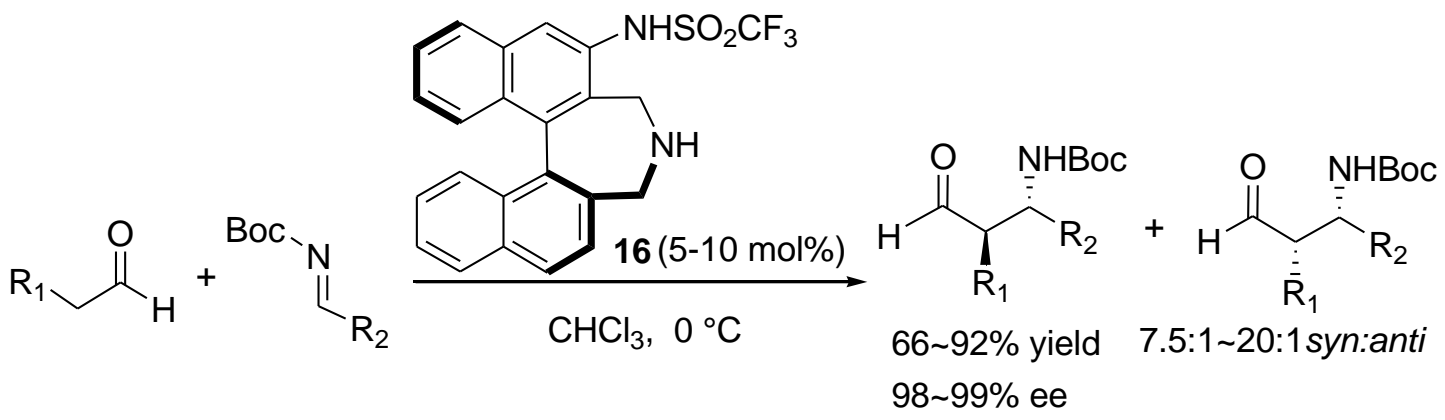

\section{Scheme 24}

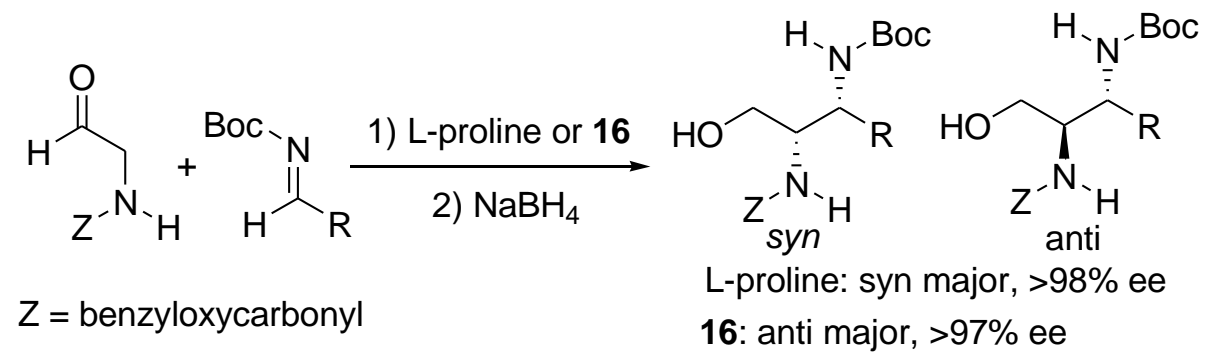

Scheme 25

In 2011, a highly efficient bisguanidine organocatalyst (17) for the Mannich-type reaction of isothiocyanato imide with N-Ts-protected imines was developed by Feng group (Scheme 26). ${ }^{47}$ Significant progress had been made with an extremely broad substrate scope, giving optically 
active $\alpha, \beta$-diamino acid derivatives in excellent yields with high diastereoselectivities (up to > 95:5 d.r.) and excellent enantioselectivities (up to $99 \%$ ee) under mild conditions. Tan et al. ${ }^{48}$ reported the highly enantio- and diastereoselective Mannich reaction catalyzed by guanidine (18) with $\alpha$-fluoro- $\beta$-keto acyloxazolidinone as the fluorocarbon nucleophile. Fluoro- $\beta$-amino acid derivatives with chiral fluorinated carbon were obtained through selective deacylation or decarboxylation reactions. Besides, the employment of $N$-tosylimines could result in remarkably efficient enantioselective anti-Mannich reactions (Scheme 27). ${ }^{49}$ The involvement of both oxygen atoms of sulfone in hydrogen bonding network to stablize the transition state was unprecedented, and might have implications for the design of novel organocatalytic systems.<smiles></smiles>

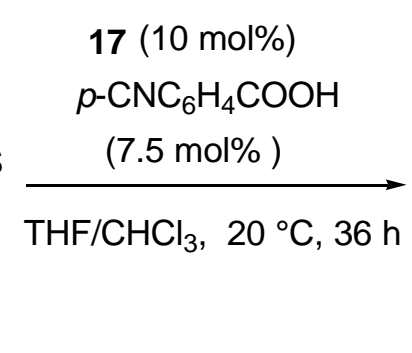<smiles>O=C1OCCN1C(=O)[C@@H]1NC(=S)N([13F])[C@H]1c1ccccc1</smiles>

$82 \sim 99 \%$ yield 80:20 >95:5 dr $90 \sim 99 \%$ ee

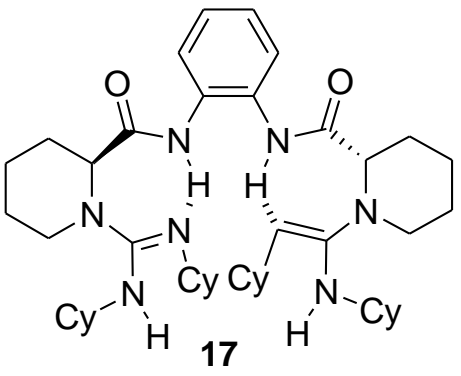

\section{Scheme 26}<smiles>CCOC(=O)/N=C(/C(=O)OCC)c1ccbcc1</smiles><smiles>[R17]c1ccc([C@H](NC(=O)OCC)C(F)(C(=O)O[Ga])C(=O)N2C(=O)OCC2(C)C)cc1</smiles>

97\% 99\% ee

\section{Scheme 27}

In 2012, Moteki et al. ${ }^{50}$ introduced to a practical synthesis of both enantiomeric Mannich products in asymmetric Mannich reactions catalyzed by catalyst (19) with or without an acid additive, and the reaction gave anti-selective Mannich reaction of a cyclic imino ester (Scheme 28). 


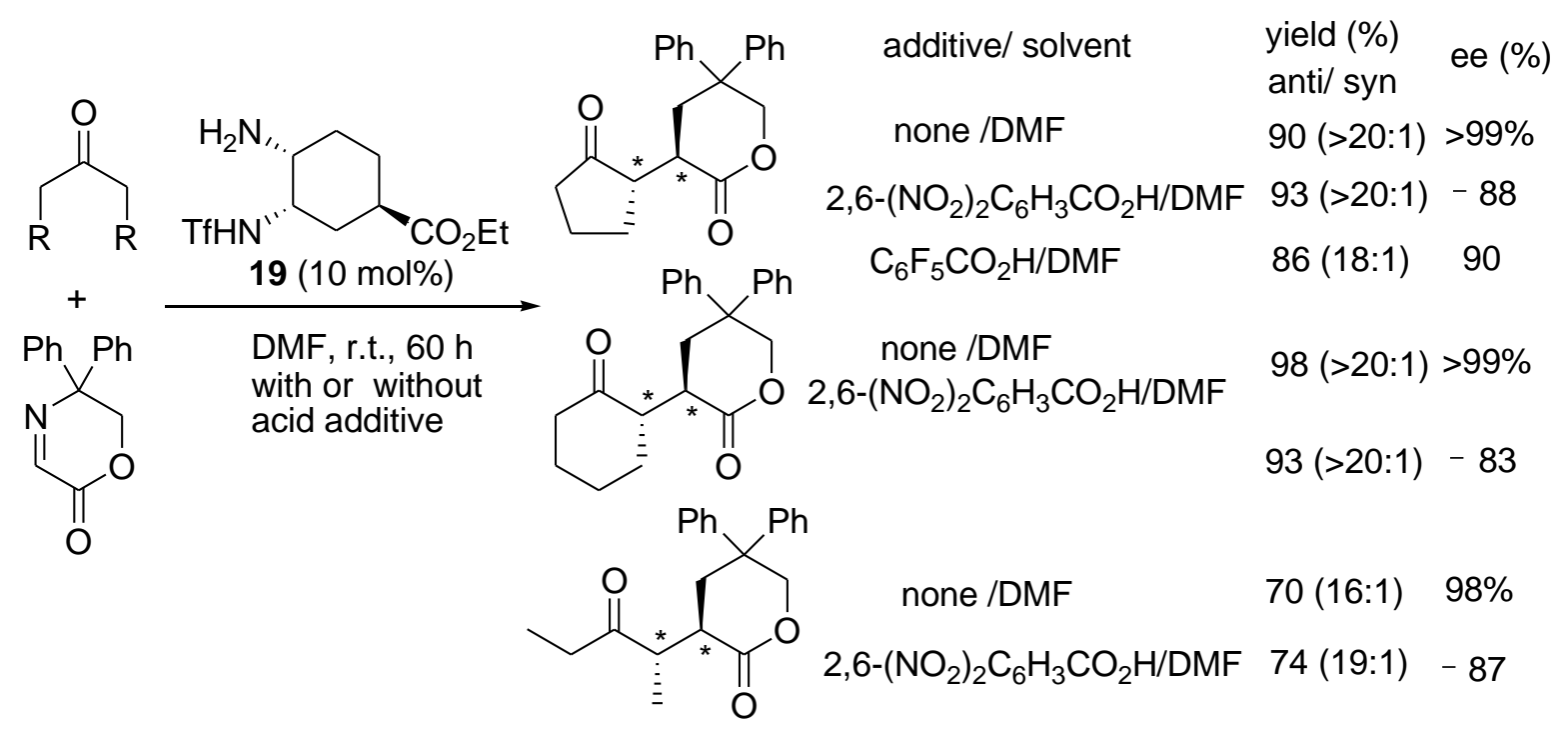

Scheme 28

\section{Catalysed by Chiral Bifunctional Thioureas}

Thiourea-catalysed reactions were already earlier reported by Jacobsen group in 2002 . The group firstly developed the thiourea-catalysed Mannich reaction that an efficient route to N-Bocprotected $\beta$-amino acids via the enantioselective addition of silyl ketene acetals to N-Boc aldimines in $2002 .{ }^{51}$ Later, this group reported again a highly enantioselective thiourea-catalyzed nitro-Mannich reactions in 2005. ${ }^{52}$

In 2008, a novel bifunctional chiral thiourea organocatalyst (20) bearing a glycosyl scaffold and a tertiary amino group starting from readily available alpha- $D$-glucose was synthesized by the Zhou group (Scheme 29). ${ }^{53}$ This thiourea was an effective organocatalyst for the asymmetric aza-Henry reaction between $N$-Boc imines and nitromethane. The corresponding adducts were obtained in good to excellent yields with highly anti-selective (93:7 99:1) and enantioselective (96 99\% ee).

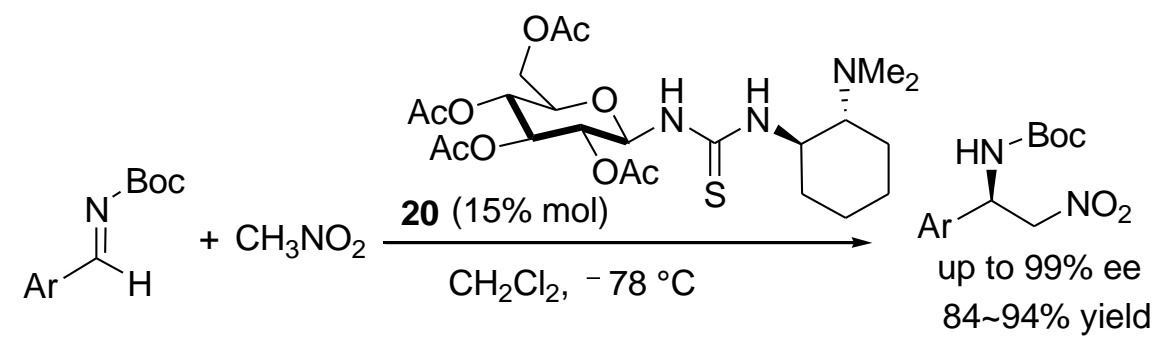

\section{Scheme 29}


The asymmetric Mannich reaction of 3-substituted oxindoles and N-Boc imines employing bifunctional thiourea-tertiary amine organocatalysts (21) based on diphenylethylene-diamine (DPEN) scaffold exhibited high diastereoselectivities. ${ }^{54}$ The corresponding Mannich adducts bearing adjacent quaternary and tertiary chiral centers were generally obtained in good to excellent enantioselectivities (up to $95 \%$ ee) (Scheme 30).

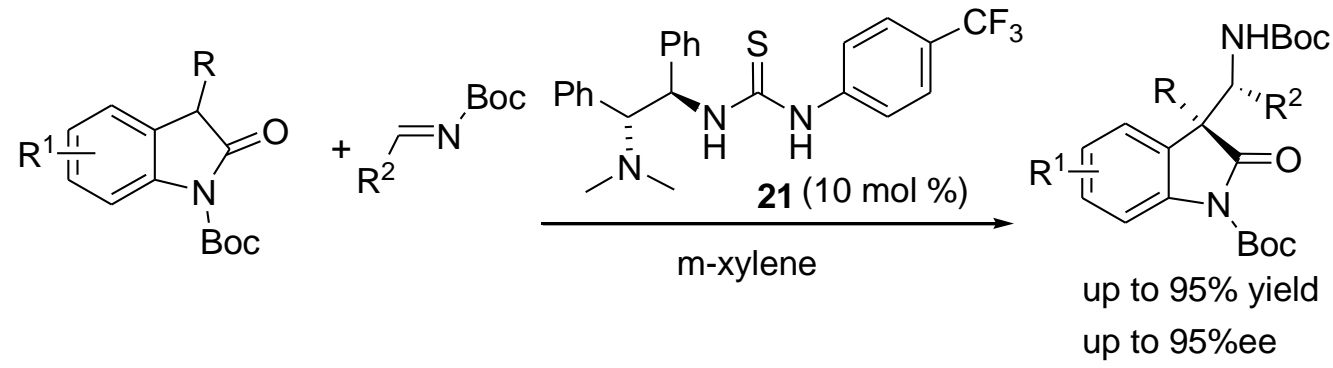

\section{Scheme 30}

Wang et al. ${ }^{55}$ developed the highly anti-selective (93:7-99:1) and excellent enantioselective (96-99\% ee) nitro-Mannich reactions catalyzed by chiral bifunctional thiourea catalyst (22) bearing multiple hydrogen-bonding donors that perform well over a broad scope of substrates (Scheme 31). This methodology was a nice complement the highly syn-selective version using a herterobimetallic $\mathrm{Cu}-\mathrm{Sm}$-Shiff base complex.

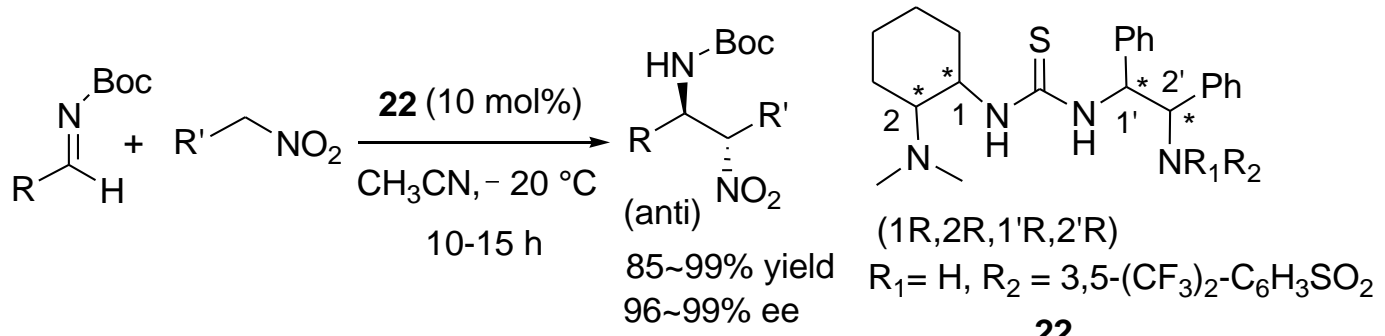

\section{Scheme 31}

Huang group ${ }^{56}$ considered a novel tryptophan based bifunctional thiourea catalyst (23) that was remarkably effective in promoting the asymmetric Mannich reaction of $\alpha$-fluoro- $\beta$ ketoesters (Scheme 32). The resulting compounds with fluorinated quaternary and tertiary stereocenters could be converted readily into $\alpha$-fluoro- $\beta$-amino acids and $\alpha$-fluoro- $\beta$-lactams. Preliminary computational studies suggested that the indole moiety of the catalyst played a crucial role in substrate binding. They disclosed that tertiary amine-thiourea bifunctional catalysts could be derived readily from natural amino acids, a strategy which may eventually lead to the discovery of various novel multifunctional organic catalysts. 


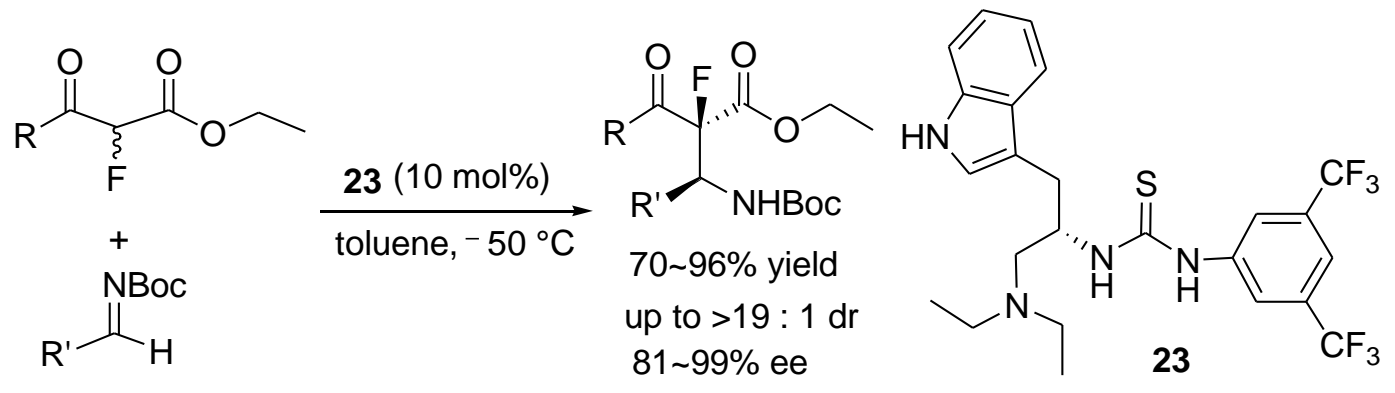

\section{Scheme 32}

In 2010, Coltart et al. ${ }^{57}$ developed the organocatalytic Mannich reaction based on proximityassisted intracomplex soft enolization of thioesters using simple derivatives of cinchona alkaloidbased catalysts (24) (Scheme 33). This approach to enolization was based on the cooperative action of a carbonyl activating hydrogen bonding (thio)urea moiety and an amine base contained within a single catalytic entity to facilitate intracomplex deprotonation. Significantly, this allowed thioesters over a range of acidity to react efficiently, thereby opening the door to the development of a general mode of enolization-based organocatalysis of monocarboxylic acid derivatives.

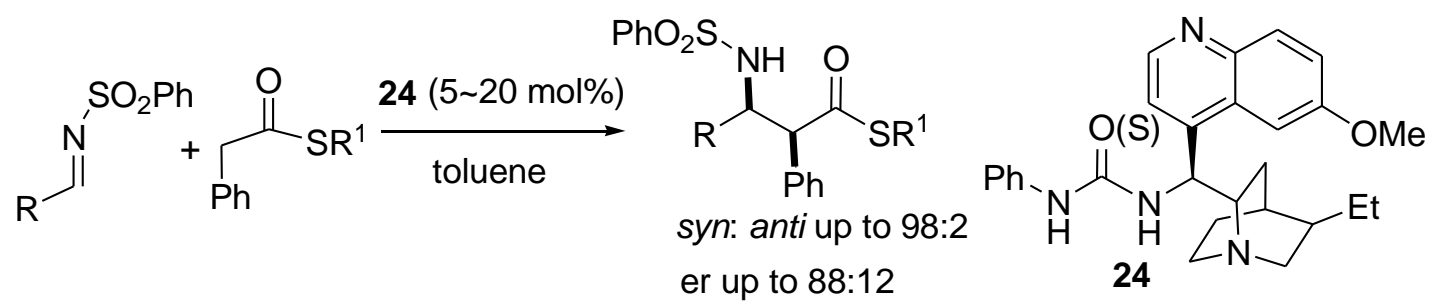

\section{Scheme 33}

Lee $e t a l .{ }^{58}$ described the highly enantioselective Mannich reaction of diethyl fluoromalonate with $N$-Boc-aldimines promoted by chiral bifunctional organocatalysts (25), and the corresponding products $\beta$-amino- $\beta$-fluoromalonates were obtained with excellent enantioselectivity (93 97\% ee) under mild reaction conditions (Scheme 34).<smiles>CCOC(=O)C(F)C(=O)OCC</smiles>

\section{Scheme 34}


In 2010, Enders et al. ${ }^{59}$ researched an efficient domino Mannich/aza-Michael reaction between carbamate-protected aryl aldimines and $\gamma$-malonate-substituted $\alpha, \beta$-unsaturated methyl esters promoted using the cinchona alkaloid catalyst $\mathbf{1 2}$ and the bifunctional thiourea catalysts $(\mathbf{2 3}, \mathbf{2 5}, \mathbf{2 6})$ (Scheme 35). The reaction furnished 2,5-cis-configured polysubstituted pyrrolidines in good to excellent yields (76 99\%), enantioselectivities (75 94\%) and excellent diastereoselectivities (de $>95 \%$ ).

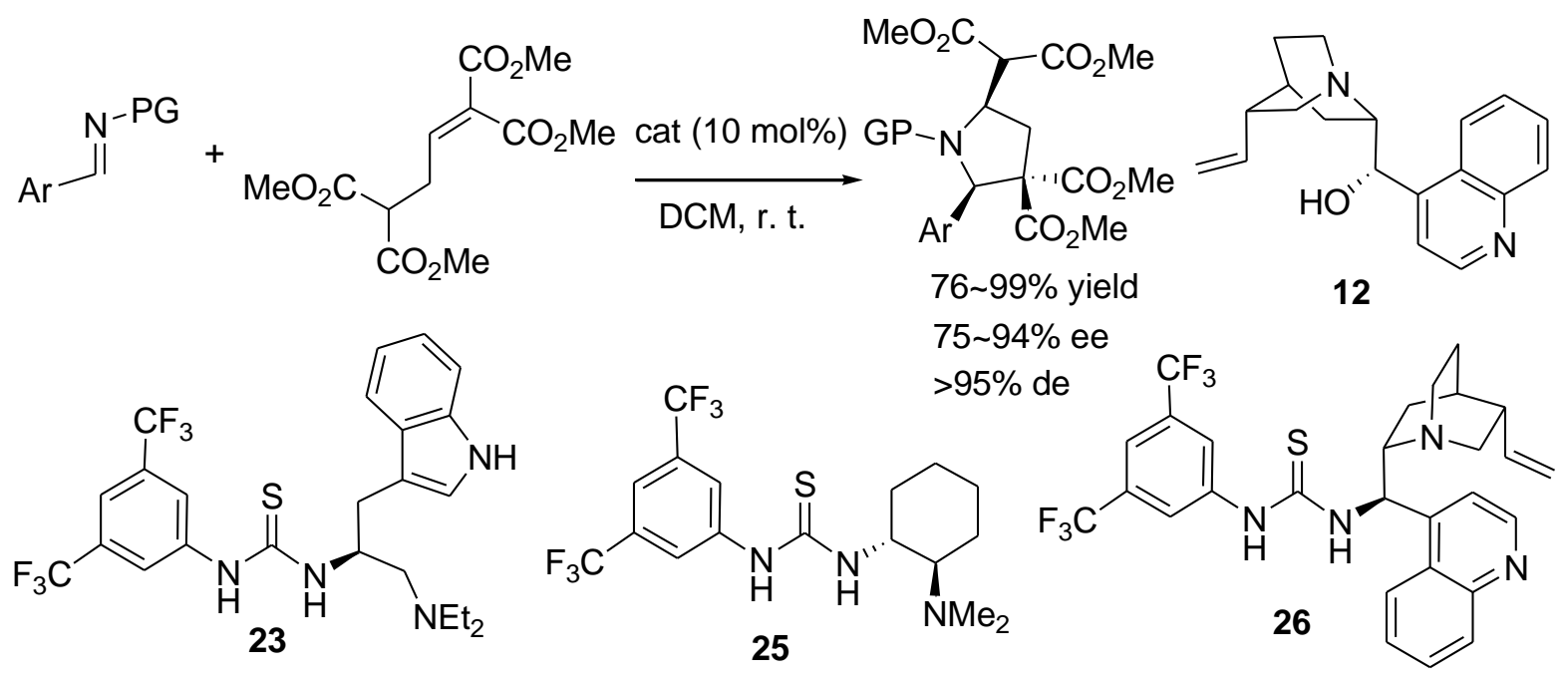

\section{Scheme 35}

Lee and $\mathrm{Kim}^{60}$ described the catalytic enantioselective electrophilic Mannich-type reaction of $\alpha$-cyano ketones with N-Boc-aldimines promoted by chiral bifunctional organocatalysts (27), and afforded the corresponding $\beta$-amino- $\alpha$-cyano ketones with excellent diastereoselectivities (up to syn/anti $=100 / 0$ ), and excellent enantioselectivities (up to $99 \%$ ee) under mild reaction conditions (Scheme 36).<smiles>CC(C)(C)OC(=O)N=CC(=O)O[Mg]</smiles><smiles>FC(F)(F)c1cc(NC(=S)NC2CCCCC2N2Cc3ccc4ccccc4c3-c3c(ccc4ccccc34)C2)cc(C(F)(F)F)c1</smiles>

\section{Scheme 36}


In 2011, Peng et al. ${ }^{61}$ identified an efficient catalytic system for the direct anti-Mannich reaction of simple aldehydes with preformed $\mathrm{N}-\mathrm{Boc}$ and $\mathrm{N}-\mathrm{Cbz}$ imines (Scheme 37). Only 5 mol\% catalyst (28) loading was needed to give the corresponding products in excellent yields (up to $95 \%$ ), diastereoselectivities (up to $96: 4 \mathrm{dr}$ ) and enantioselectivities (up to >99\% ee).

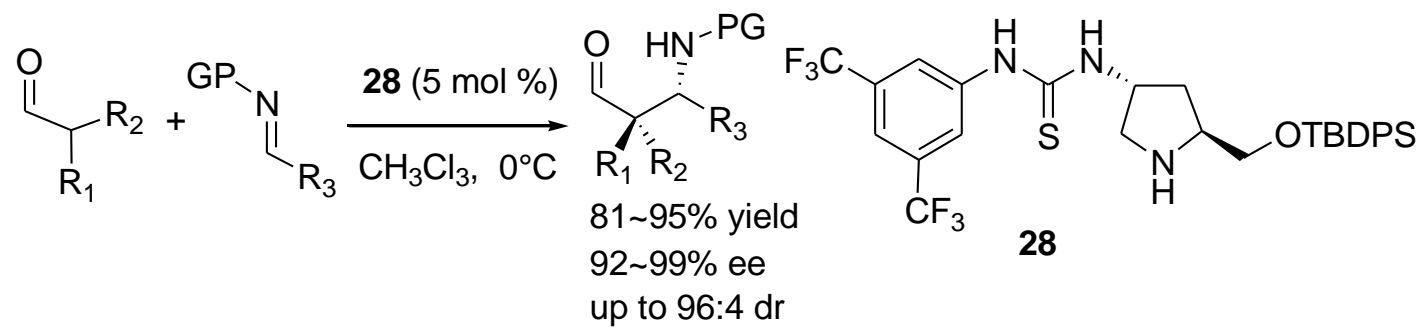

\section{Scheme 37}

Recently, Luo et al. ${ }^{62}$ reported the synthesis of 3,3-disubstituted phthalide derivatives using a quinidine-based multifunctional catalyst (29) in excellent yields, with good diastereo- and enantioselectivities (Scheme 38). The method led to convenient synthesis of chiral isoquinolinones and isoquinolines had also been demonstrated.

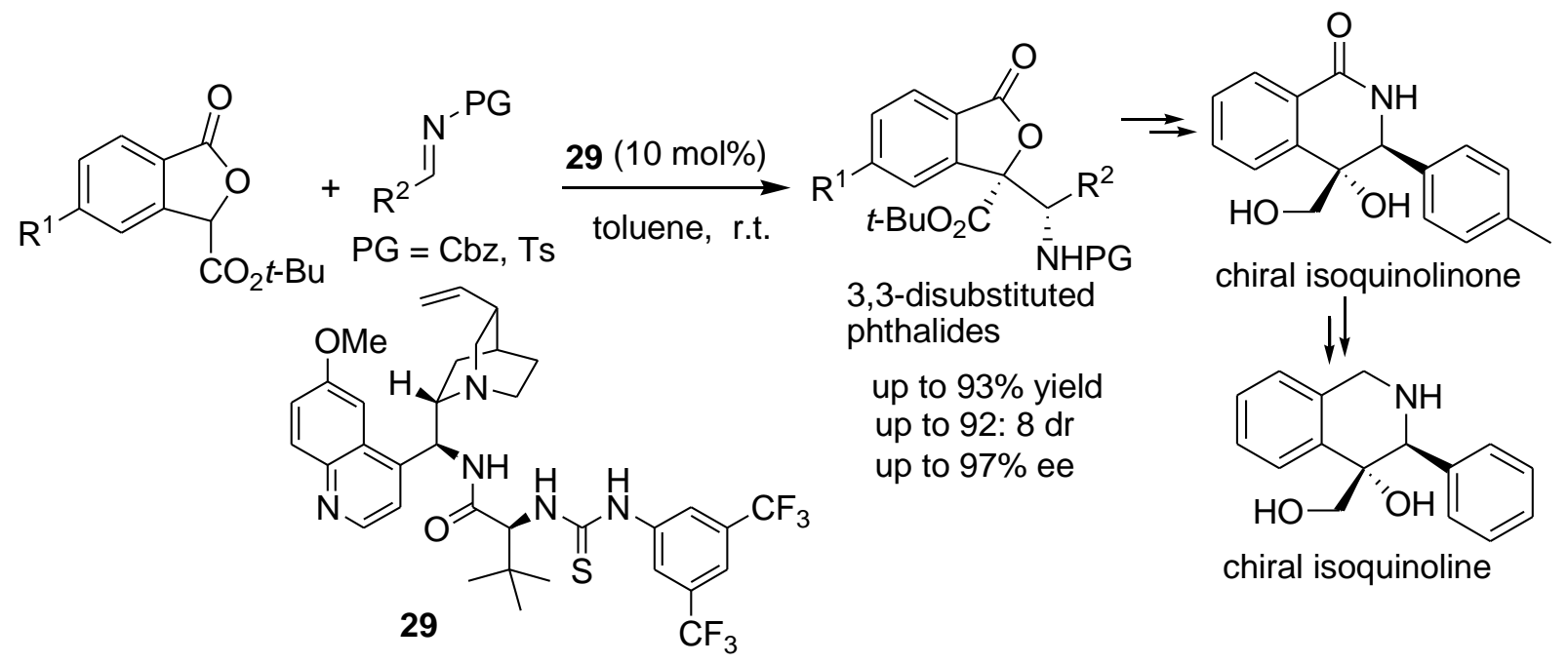

\section{Scheme 38}

In 2011, Peng et al. $^{63}$ achieved the asymmetric nitro-Mannich reactions of nitroalkanes and in situ generated $\mathrm{N}$-Boc-imines using a new type of thiourea-guanidine bifunctional organocatalyst (30). The novel transformations exhibited good diastereoselectivities, and the adducts bearing adjacent chiral centers were generally obtained in moderate to high enantioselectivities (up to $94 \%$ ee). This reaction provided a concise and alternative route converting readily accessible and stable $\mathrm{N}$-carbamate amido sulfones into optically active 1,2diamino compounds (Scheme 39). 


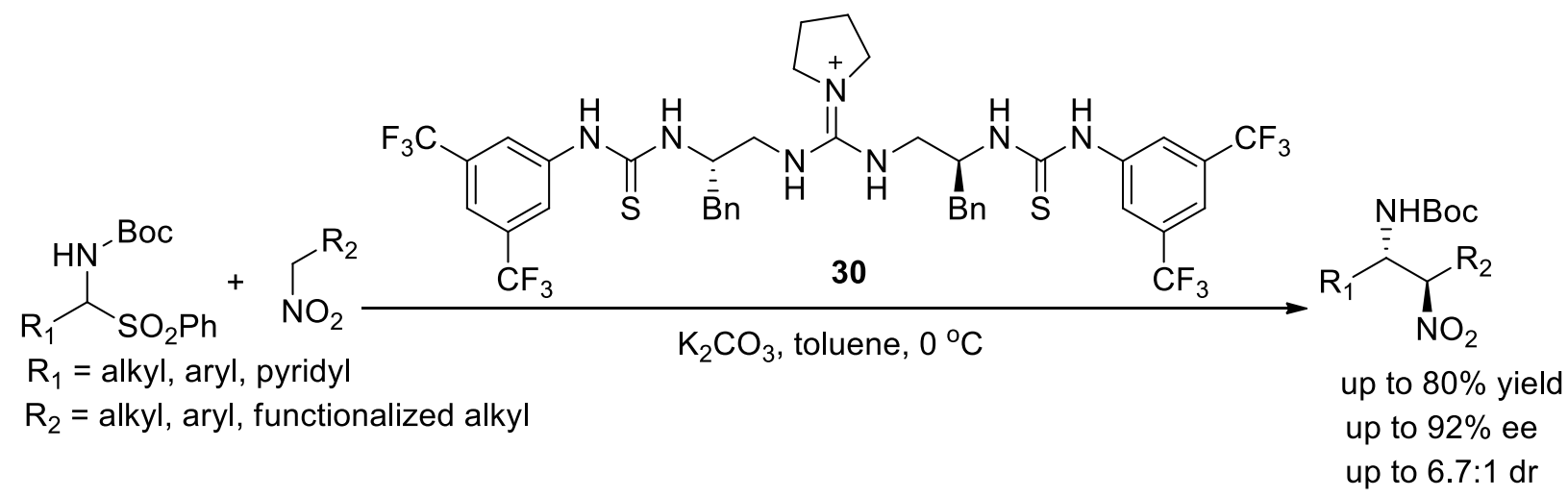

\section{Scheme 39}

\section{Catalysed by Chiral Brønsted Acids}

It was an important pathway for enantioselective organocatalysed Mannich reactions proceeds via enantiopure Brønsted acids. As an early example, Akiyama et $a l .{ }^{64,65}$ reported enantioselective Mannich-type reaction of aldimines with silyl enolates, and $\beta$-aminoesters catalysed by a series of chiral phosphate catalysts, of which phosphoric acid proved to give the best results.

Schneider and co-workers ${ }^{66}$ developed that vinylketene silyl $\mathrm{N}, \mathrm{O}$-acetals readily participate vinylogous Mukaiyama-Mannich reactions catalyzed by Brønsted acid (31) with aromatic and heteroaromatic aldimines, and afforded $\delta$-amino- $\alpha, \beta$-unsaturated amides in good yields and enantioselectivities (Scheme 40). Direct three-component vinylogous Mannich reactions produced the products with almost identical yield and enantioselectivity, thus avoiding the synthesis of the imines in a separate step. The utility of the vinylogous Mannich products was demonstrated through conversion into various functional building blocks including a short synthesis of the enantiomerically highly enriched 2-phenylpiperidine. In 2010, Magnus and Lin ${ }^{67}$ developed the enantioselective domino Mannich-ketalization reaction of $o$-hydroxy benzaldimines with electron-rich alkenes promoted by Brønsted acid (32) afforded an effective and direct access to optically pure 4-aminobenzopyrans in good yields with excellent enantiomeric ratios (up to 98:2 er) (Scheme 41). 


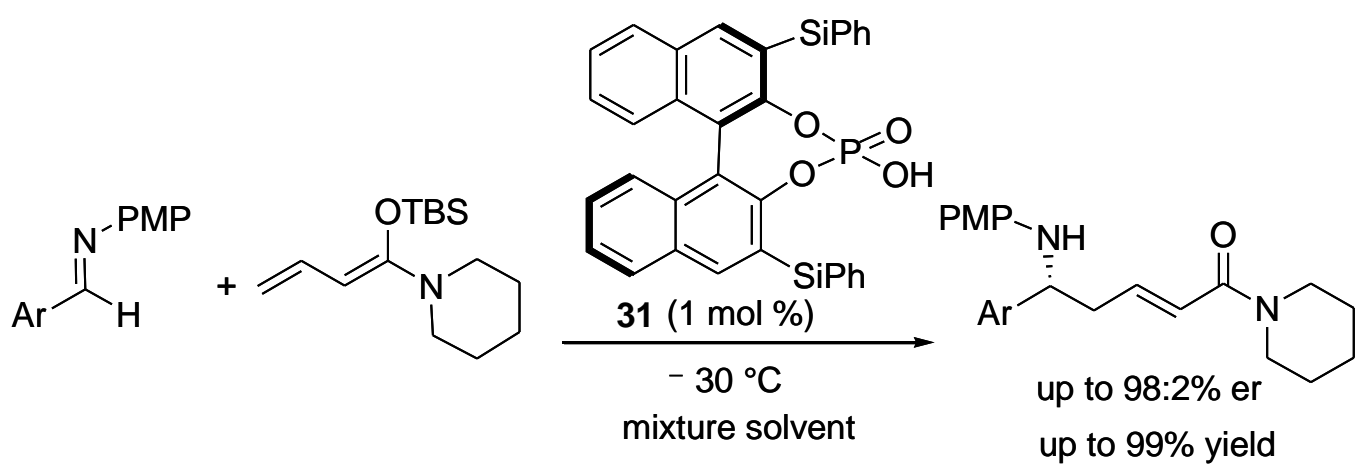

\section{Scheme 40}

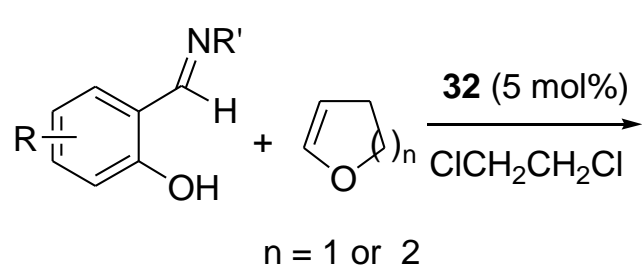<smiles>[R]N[C@H]1c2ccccc2O[C@@H]2O[C@H]1[C@H]2O</smiles>
up to $88 \%$ yield up to $33: 1 \mathrm{dr}$ up to $98: 2$ er<smiles>O=P(O)(NS(=O)(=O)Oc1c(Br)cc2c(c1-c1c(Br)cc3c(c1Br)CCCC3)CCCC2)OC(F)(F)F</smiles>

$\operatorname{Ar}=9$-phenanthryl 32

\section{Scheme 41}

BINSA (33) were a highly effective chiral Brønsted acid that could be combined with an achiral Brønsted base. In 2008, Ishihara et al. ${ }^{68}$ reported a direct Mannich-type reactions of a variety of 1,3-diketones and a 1,3-ketoester equivalent with arylaldimines proceeded smoothly with high enantioselectivities in the presence of 1 mol \% of BINSA and 2 mol \% of 2,6biarylpyridine (Scheme 42). They thank that BINSA should be a powerful chiral auxiliary like BINOL, BINAP (2,2'-bis(diphenylphosphino)-1,1'-binaphthalene), BINAM (2,2'-diamino-1,1'binaphthalene), etc., and could trigger a new frontier in acid-base chemistry in asymmetric catalyses.

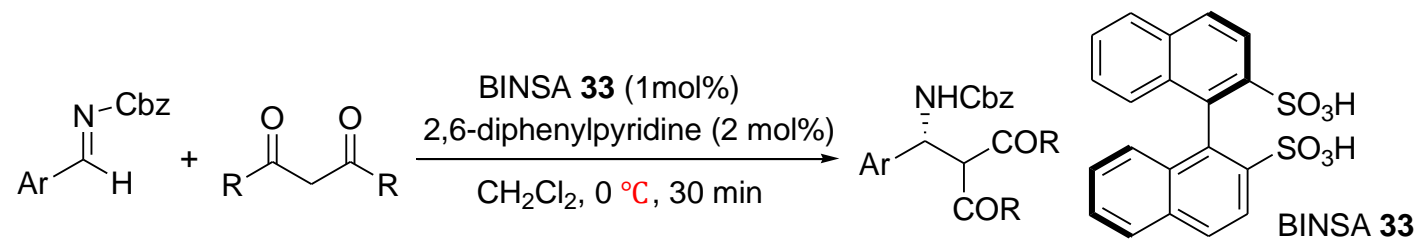

\section{Scheme 42}

In 2012, Chen et al. ${ }^{69}$ reported an efficient and highly sterically hindered Brønsted acid catalyst (34) in asymmetric three-component Mannich reactions, and optically active syn- $\beta$ - 
amino ketones were obtained in high yields (up to 99\%) with excellent diastereoselectivity (99:1) and enantioselectivity (up to $99 \%$ ee) (Scheme 43). A gram-scale reaction was also performed to prove the synthetic application value of this reaction.

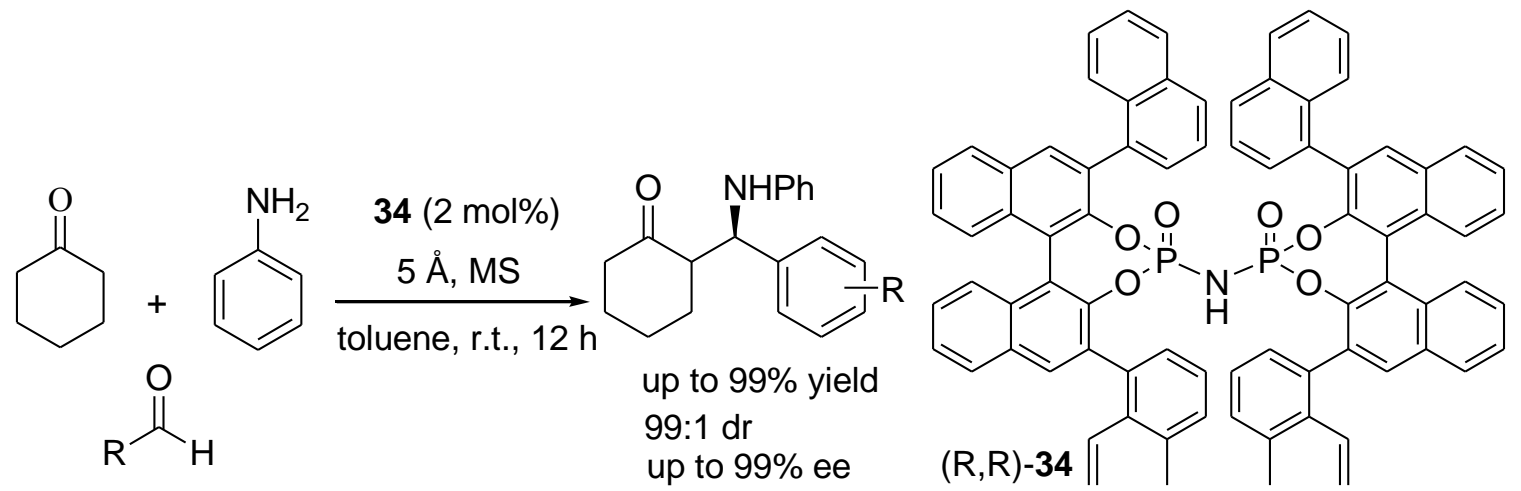

Scheme 43

\section{Catalysed by Other Chiral Organocatalytic Systems}

Hajra et $a .^{70}$ found that imidazole-based zwitterionic-type molten salts (35) were new class of catalysts for the aza-Henry reaction in excellent yields and with highly selectivity (Scheme 44). Most significantly, the syn- $\beta$-nitroamine was obtained predominantly under the present reaction conditions.<smiles>[R]NC([R])C([R])N[R]([H])=O</smiles>

\section{Scheme 44}

In 2010, Wang et al. $^{71}$ reported the employment of CIL [EMIm][Pro] (36) as a catalyst for the one-pot three-component asymmetric Mannich reaction with excellent chemo-, regio-, and enantioselectivities either under mild conditions or at a low temperature (Scheme 45). The desired products were isolated in up to $99 \%$ yield and with up to > $99 \mathrm{dr}$ and $>99 \%$ ee. Additionally, this catalyst was readily prepared from rather inexpensive starting materials and the reactions could be conducted in wet solvent without an inert atmosphere. The proposed mechanism and transition state had been discussed on the basis of the stereochemistry of the corresponding Mannich products. 


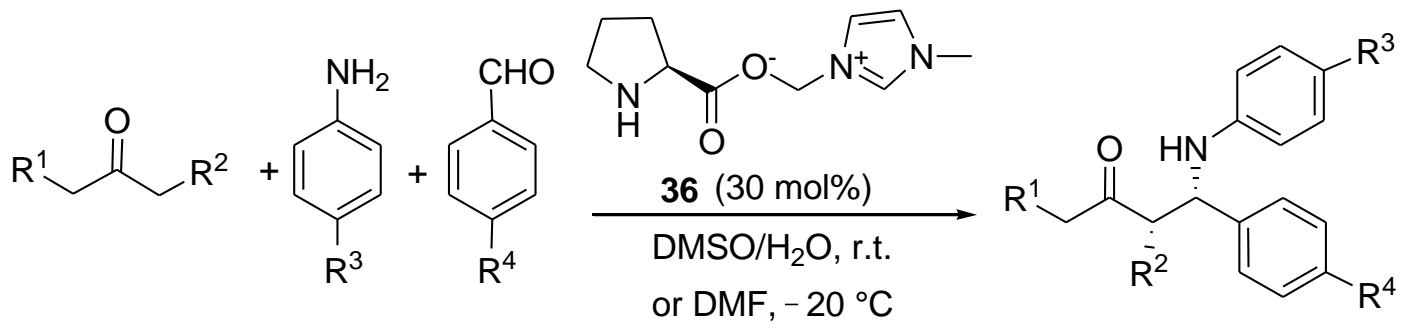

\section{Scheme 45}

Bernardi and Ricci group ${ }^{72}$ reported the asymmetric Mannich-type reaction of different malonates and $\beta$-ketoesters could react with $N$-tert-butoxycarbonyl-( $N$-Boc) and $N$ benzyloxycarbonyl-(N-Cbz) protected $\alpha$-amido sulfones was promoted using phase-transfer catalyst (37) under very mild and user-friendly conditions (Scheme 46). The optimised protocol avoided the preparation and the isolation of the relatively unstable N-Boc and N-Cbz imines that were generated in situ from the bench-stable $\alpha$-amido sulfones. The corresponding Mannich bases were generally obtained in good yields and enantioselectivities, and could be readily transformed into key compounds, such as optically active $\beta$-amino acids in one simple step.

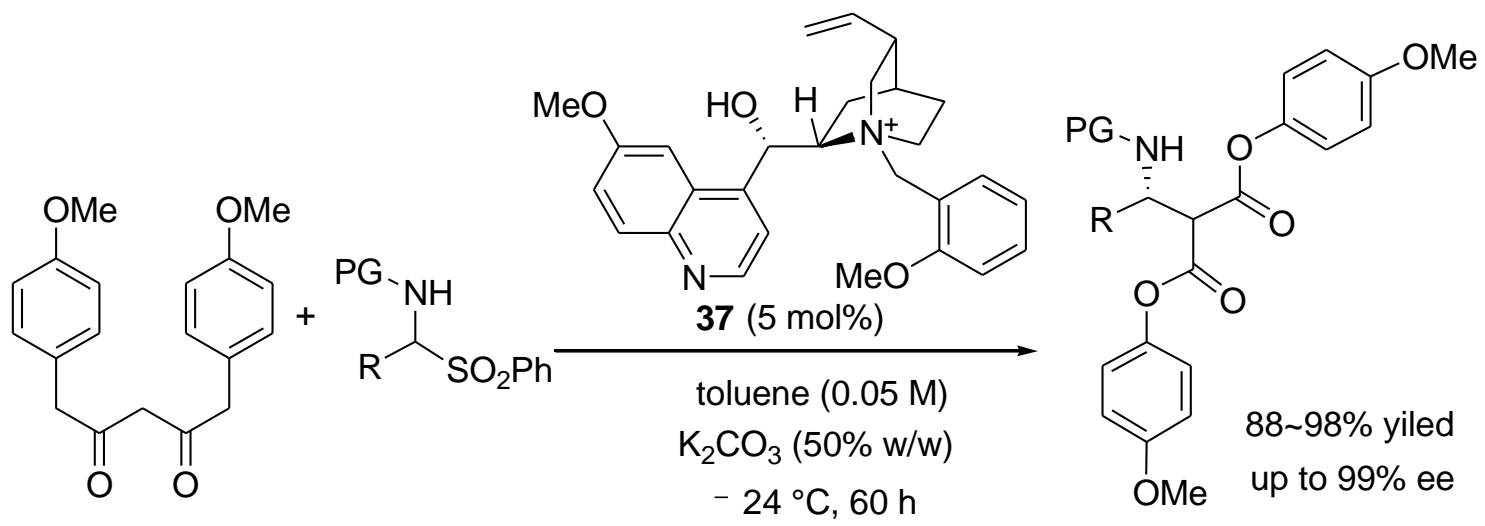

\section{Scheme 46}

Recently, Pitchumani et $a{ }^{73}{ }^{73}$ developed a highly efficient diastereoselective Mannich reaction has been carried out in water using a catalytic amount of $\beta$-cyclodextrin (38) as a chiral host in the presence of acetic acid to give the corresponding $\beta$-aminoketones (Mannich bases) with good yield (up to 98\%) and excellent diastereomeric excess (up to >99\%) (Scheme 47). This Brønsted acid-chiral cyclodextrin composite catalyzed reaction proceeds in a syn-selective manner with 98:2 syn/anti selectivity when propiophenone was used as the ketone moiety and in an anti-selective manner with 100:0 (anti/syn) selectivity when cyclohexanone was used. 


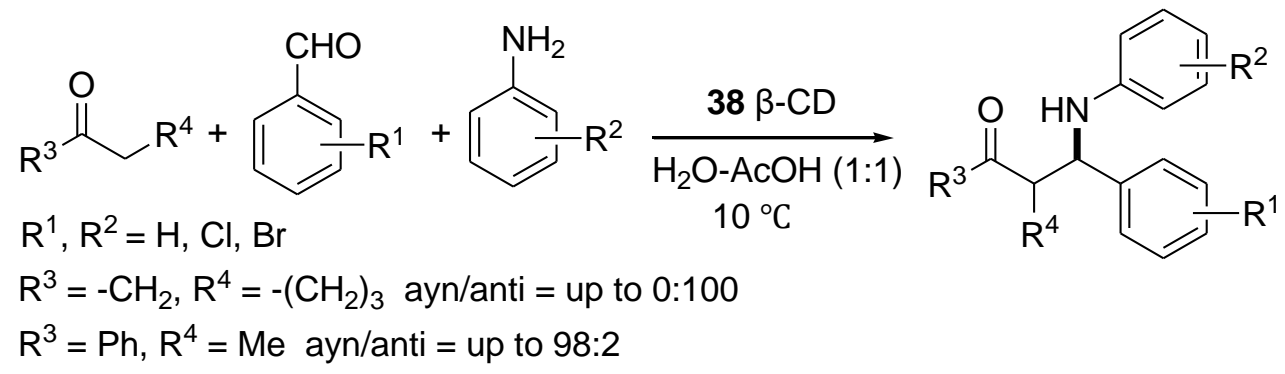

\section{Scheme 47}

\section{Discussion}

This review demonstrates clearly the diversity and power of organocatalysed asymmetric Mannich reactions. The use of proline and derivatives as the catalyst affords easy access to synproducts in good yields with high regio-, diastereo- and enantioselectivity, but pyrrolidine derivatives as the catalyst mainly gives to the anti-products. Chiral cinchona alkaloids, bifunctional thioureas and their derivatives have also been successfully employed in combination with electron-poor imines and active methylene compounds with high diastereo- and enantioselectivity. Chiral Brønsted acids (mostly phosphoric acids) have been employed to include the iminium ion in a chiral ion pair, which also results in enantioselective addition onto the iminium species. Besides, other chiral organocatalytic systems have been used and exhibited the exciting results in organocatalysed asymmetric Mannich reactions in recent years, For example, the using of chiral ion and chiral phase-transfer catalyst consulting in good yields as well as highly regio-, and enantioselectivities. Transition-metal-catalysed enantioselective reactions will certainly continue to play a central role in the future; however, metal-free catalysts appear to be an emerging trend over the past few years in asymmetric Mannich reactions. In past few years, enantioselective organocatalytic asymmetric Mannich reactions have obtained rapid development, regarding the applications of this type of reactions, but efforts must be directed to research highly enantioselective and new type of chiral organocatalysts, in particular, and develop some procedures could be valuable to practical application in asymmetric Mannich reactions.

\section{Acknowledgements}

We thank the National Natural Science Foundation of China (20962006) and the Natural Science Foundation of the Guizhou Science and Technology Department (LKM[2011]) for financial support. 


\section{References}

1. Cordova, A. Acc. Chem. Res. 2004, 37, 102.

http://dx.doi.org/10.1021/ar0302311

PMid:14967057

2. Kobayashi, S.; Ishitani, H.; Kobayashi, S.; Ishitani, H. Chem. Rev. 1999, 99, 1069.

http://dx.doi.org/10.1021/cr980414z

PMid:11749440

3. Arend, M.; Westermann, B.; Risch, N. Angew. Chem. Int. Ed. 1998, 37, 1044.

http://dx.doi.org/10.1002/(SICI)1521-3773(19980504)37:8<1044::AID-ANIE1044>3.0.CO;2-E

4. Arrayás, R. G. and Carretero, J. C. Chem. Soc. Rev. 2009, 38, 1940.

http://dx.doi.org/10.1039/b820303b

PMid:19551174

5. Verkade, J. M. M.; van Hemert, L. J. C.; Quaedflieg, P. J. L. M.; Rutjes, F. P. J. T. Chem. Soc. Rev. 2008, 37, 29.

http://dx.doi.org/10.1039/b713885g

PMid:18197331

6. Pellissier, H. Tetrahedron 2007, 63, 9267.

http://dx.doi.org/10.1016/j.tet.2007.06.024

7. Graaff, C. D.; Ruijter, E. and Orru, R. V. A. Chem. Soc. Rev. 2012, 41, 3969.

http://dx.doi.org/10.1039/c2cs15361k

PMid:22546840

8. Ma, J. A. Angew. Chem. Int. Ed. 2003, 42, 4290.

http://dx.doi.org/10.1002/anie.200301600

PMid:14502699

9. Liu, M.; Sibi, M. P. Tetrahedron 2002, 58, 7991.

http://dx.doi.org/10.1016/S0040-4020(02)00991-2

10. Müller, R.; Goesmann, H.; Waldmann, H. Angew. Chem. Int. Ed. 1999, 38, 184.

http://dx.doi.org/10.1002/(SICI)1521-3773(19990115)38:1/2<184::AID-ANIE184>3.0.CO;2-E

11. Shibasaki, M.; Matsunaga, S. J. Organomet. Chem. 2006, 691, 2089.

http://dx.doi.org/10.1016/j.jorganchem.2005.10.025

12. Friestad, G. K.; Mathies, A. K. Tetrahedron 2007, 63, 2541.

http://dx.doi.org/10.1016/j.tet.2006.11.076

13. Charette, A. B.; Boezio, A. A.; Cote, A.; Moreau, E.; Pytkowicz, J.; Desrosiers, J. N.;

Legault, C. Pure Appl. Chem. 2005, 77, 1259.

http://dx.doi.org/10.1351/pac200577071259

14. Chen, Z. H.; Yakura, K.; Matsunaga, S. and Shibasaki M. Org. Lett. 2008, 10, 3239.

http://dx.doi.org/10.1021/ol800965t

PMid:18610973 
15. Wang, J.; Shi, T.; Deng, G. H.; Jiang, H. L. and Liu, H. J. Org. Chem. 2008, 73, 8563. http://dx.doi.org/10.1021/jo8019169

PMid:18844412

16. Shepherd, N. E.; Tanabe, H.; Xu, Y. J.; Matsunaga, S. and Shibasaki, M. J. Am. Chem. Soc. 2010, 132, 3666.

http://dx.doi.org/10.1021/ja1002636

PMid:20192184

17. Kang, Y. K.; Kim, D. Y. Tetrahedron Lett. 2011, 52, 2356.

http://dx.doi.org/10.1016/j.tetlet.2011.02.087

18. List, B.; Pojarliev, P.; Biller, W. T.; Martin, H. J. J. Am. Chem. Soc. 2002, 124, 827.

http://dx.doi.org/10.1021/ja0174231

19. Chandler, C.; Galzerano, P.; Michrowska, A. and List, B. Angew. Chem. Int. Ed. 2009, 48, 1978.

http://dx.doi.org/10.1002/anie.200806049

PMid:19199308

20. Mukherjee, S.; Yang, J. W.; Hoffmann, S.; List, B. Chem. Rev. 2007, 107, 5471. http://dx.doi.org/10.1021/cr0684016

PMid:18072803

21. List, B.; Pojarliev, P.; Biller, W. T. and Martin, H. J. J. Am. Chem. Soc. 2002, 124, 827.

http://dx.doi.org/10.1021/ja0174231

22. Han, R. -G.; Wang, Y.; Li, Y. -Y. and Xu P. F. Adv. Synth. Cat. 2008, 350, 1474

http://dx.doi.org/10.1002/adsc.200800253

23. Hahn, B. T.; Fröhlich, R.; Harms, K. and Glorius, F. Angew. Chem. Int. Ed. 2008, 47, 9985. http://dx.doi.org/10.1002/anie.200803515

PMid:19006133

24. Deiana, L.; Zhao, G. -L.; Dziedzic, P.; Rios, R.; Vesely, J.; Ekstr, J.; Córdova, A.

Tetrahedron Lett. 2010, 51, 234.

http://dx.doi.org/10.1016/j.tetlet.2009.10.130

25. Li, L. Q.; Han, M. Y.; Xiao, M. X.; Xie, Z. X. Synlett 2011,1727.

26. Yang, H. Carter, R. G. J. Org. Chem. 2009, 74, 5151.

http://dx.doi.org/10.1021/jo9009062

PMid:19743541

27. Veverkova, E.; Strasserova, J.; Sebesta, R.; Toma, S. Tetrahedron: Asymmetry 2010, 21, 58. http://dx.doi.org/10.1016/j.tetasy.2009.12.013

28. Lu, M.; Lu, Y. P.; Tan, P. K. A.; Lau, Q. Y.; Zhong, G. F. Synlett 2011, 477.

29. An, Y. -J.; Wang, C. -C.; Liu, Z. -P. and Tao, J. -C. Helv. Chim. Acta 2012, 95, 43.

http://dx.doi.org/10.1002/hlca.201100265

30. Franzén, J.; Marigo, M.; Fielenbach, D.; Wabnitz, T. C.; Kjærsgaard, A.; Jørgensen, K. A. J. Am. Chem. Soc. 2005, 127, 18296. 
http://dx.doi.org/10.1021/ja056120u

PMid:16366584

31. Gianelli, C.; Sambri, L.; Carlone, A.; Bartoli, G. and Melchiorre, P. Angew. Chem. Int. Ed. 2008, 47, 8700 .

http://dx.doi.org/10.1002/anie.200803819

PMid:18846535

32. Fustero, S.; Mojarrad, F.; Carrión, M. D. P.; Sanz-Cervera, J. F. and Ace-a, J. L. Eur. J. Org. Chem. 2009, 5208.

http://dx.doi.org/10.1002/ejoc.200900509

33. Galzerano, P.; Agostino, D.; Bencivenni, G.; Sambri, L.; Bartoli, G.; Melchiorre P. Chem.

Eur. J. 2010, 16, 6069.

PMid:20397160

34. Urushima, T.; Ishikawa, H. and Hayashi,Y. Chem. Eur. J. 2011, 17, 8273.

http://dx.doi.org/10.1002/chem.201101077

PMid:21656864

35. Hayashi,Y.; Urushima, T.; Sakamoto, D.; Torii, K.; Ishikawa, Hayato. Chem. Eur. J. 2011, $17,11715$.

http://dx.doi.org/10.1002/chem.201101668

PMid:21887838

36. Gómez-Bengo, E.; Maestro, M.; Mielgo, A.; Otazo, I.; Palomo, C. and Velill, I. Chem. Eur. J. $2010,16,5333$.

37. Gómez-Bengoa, E.; Jiménez, J.; Lapuerta, I.; Mielgo, A.; Oiarbide, M.; Otazo, I.; Velilla, I.; Vera, S. and Palomo, C. Chem. Sci. 2012, 3, 2949.

http://dx.doi.org/10.1039/c2sc20590d

38. Pouliquen, M.; Blanchet, J.; Lasne, M. -C. and Rouden, J. Org. Lett. 2008, 10, 1029.

http://dx.doi.org/10.1021/o18000975

PMid:18225912

39. Zhang, H. L.; Mitsumori, S.; Utsumi, N.; Imai, M.; Garcia-Delgado, N.; Mifsud, M.;

Albertshofer, K.; Cheong, P. H. -Y.; Houk, K. N.; Tanaka, F. J. and Barbas, C. F. C. J. Am.

Chem. Soc. 2008, 130, 875.

http://dx.doi.org/10.1021/ja074907+

PMid:18163619

40. Hayashi, Y.; Urushima, T.; Aratake, S.; Okano, T. and Obi, K. Org. Lett. 2008, 10, 21.

http://dx.doi.org/10.1021/ol702489k

PMid:18052181

41. Lou, S.; Dai, P. and Schaus, S. E. J. Org. Chem. 2007, 72, 9998.

http://dx.doi.org/10.1021/jo701777g

PMid:18047372 
42. Liu, X. D.; Deng, L. J.; Song, H. J.; Jia, H. Z. and Wang, R. Org. Lett. 2011, 13, 1494.

http://dx.doi.org/10.1021/ol200185h

PMid:21344918

43. Mizuta, S.; Shibata, N.; Goto, Y.; Furukawa, T.; Nakamura, S. and Toru, T. J. Am. Chem. Soc. 2007, 129, 6394.

http://dx.doi.org/10.1021/ja071509y

PMid:17461589

44. Kano, T.; Yamaguchi, Y. and Maruoka, K. Chem. Eur. J. 2009, 15, 6678.

http://dx.doi.org/10.1002/chem.200900267

PMid:19479934

45. Kano, T.; Yamaguchi, Y. and Maruoka, K. Angew. Chem. Int. Ed. 2009, 48, 1838.

http://dx.doi.org/10.1002/anie.200805628

PMid:19173354

46. Kano, T.; Sakamoto, R.; Akakura, M. and Maruoka, K. J. Am. Chem. Soc. 2012, 134, 7516.

http://dx.doi.org/10.1021/ja301120z

PMid:22486203

47. Chen, X. H.; Dong, S. X.; Qiao, Z.; Zhu, Y.; Xie, M. S.; Lin, L. L.; Liu, X. H. and Feng, X.

M. Chem. Eur. J. 2011, 17, 2583.

http://dx.doi.org/10.1002/chem.201002571

PMid:21271617

48. Pan,Y. H.; Zhao, Y. J.; Ma, T.; Yang, Y. Y.; Liu, H. J.; Jiang, Z. Y. and Tan, C. -H. Chem. Eur. J. 2010, 16, 779.

PMid:19943289

49. Cheng, L. L.; Han, X.; Huang, H. M.; Wong, W. and Lu, Y. X. Chem. Commun. 2007, 4143.

http://dx.doi.org/10.1039/b706793c

PMid:17925956

50. Moteki, S. A.; Han, J. W.; Arimitsu, S.; Akakura, M.; Nakayama, K.; Maruoka, K. Angew.

Chem. Int. Ed. 2012, 51, 1187.

http://dx.doi.org/10.1002/anie.201107239

PMid:22190385

51. Wenzel, A. G. and Jacobsen, E. N. J. Am. Chem. Soc. 2002, 124, 12964.

http://dx.doi.org/10.1021/ja028353g

52. Yoon, T. P. and Jacobsen, E. N. Angew. Chem. Int. Ed. 2005, 44, 466.

http://dx.doi.org/10.1002/anie.200461814

PMid:15624148

53. Wang, C. G.; Zhou, Z. H. and Tang, C. C. Org. Lett. 2008, 10, 1707.

http://dx.doi.org/10.1021/o18003035

PMid:18396893 
54. Tian, X.; Jiang, K.; Peng, J.; Du, W. and Chen, Y. -C. Org. Lett. 2008, 10, 3583.

http://dx.doi.org/10.1021/ol801351j

PMid:18642826

55. Wang, C. -J.; Dong, X. -Q.; Zhang, Z. -H.; Xue, Z. -Y. and Teng, H. -L. J. Am. Chem. Soc. 2008, 130, 8606.

http://dx.doi.org/10.1021/ja803538x

PMid:18549213

56. Han, X.; Kwiatkowski, J.; Xue, F.; Huang, K. -W. and Lu, Y. X. Angew. Chem. Int. Ed. 2009, 48, 7604.

57. Kohler, M. C.; Yost, J. M.; Garnsey, M. R. and Coltart, D. M. Org. Lett. 2010, 12, 3376.

http://dx.doi.org/10.1021/ol101152b

PMid:20608684

58. Lee. L. J. and Young, K. D. Synthesis 2010, 1860.

59. Enders, D.; Göddertz, D. P.; Bece-e, C. and Raabe, G. Adv. Synth. Catal. 2010, 352, 2863.

http://dx.doi.org/10.1002/adsc.201000658

60. Lee, J. H. and Kim, D. Y. Adv. Synth. Catal. 2009, 351, 1779.

http://dx.doi.org/10.1002/adsc.200900268

61. Chuan, Y. -M.; Chen, G. -H.; Gao, J. -Z.; Zhang, H. and Peng, Y. -G. Chem. Commun. 2011, 47,3260 .

http://dx.doi.org/10.1039/c0cc05249c

PMid:21283837

62. Luo, J.; Wang, H. F.; Zhong, F. R.; Kwiatkowski, J.; Xu, L.W. and Lu, Y. X. Chem.

Commun. 2012, 48, 4707.

http://dx.doi.org/10.1039/c2cc31439h

PMid:22488217

63. Huang, W., Peng, C.; Guo, L.; Hu, R.; Han, B. Synlett 2011, 20, 2981.

64. Takahiko, A.; Itoh, J.; Yokota, K. and Fuchibe, K. Angew. Chem. Int. Ed. 2004, 43, 1566.

http://dx.doi.org/10.1002/anie.200353240

PMid:15022235

65. Yamanaka, M.; Itoh, J.; Fuchibe, K.; Akiyama, T. J. Am. Chem. Soc. 2007, 129, 6756.

http://dx.doi.org/10.1021/ja0684803

PMid:17477527

66. Giera, D.S.; Sickert, M. and Schneider, C. Org. Lett. 2008, 10, 4259.

http://dx.doi.org/10.1021/o18017374

PMid:18754625

67. Rueping, M. and Lin, M. -Y. Chem. Eur. J. 2010, 16, 4169.

http://dx.doi.org/10.1002/chem.201000203

PMid:20309979

68. Hatano, M.; Maki, T.; Moriyama, K.; Arinobe, M.; Ishihara, K. J. Am. Chem. Soc. 2008, 130, 16858. 
http://dx.doi.org/10.1021/ja806875c

PMid:19053478

69. Chen, Y. -Y.; Jiang, Y. -J.; Fan, Y.-S.; Sha, D.; Wang, Q. F.; Zhang, G. L.; Zheng, L. Y.;

Zhang, S. Q. Tetrahedron: Asymmetry 2012, 23, 904.

http://dx.doi.org/10.1016/j.tetasy.2012.06.008

70. Kundu, D.; Debnath, R. K.; Majee, A.; Hajra, A. Tetrahedron Lett. 2009, 50, 6998.

http://dx.doi.org/10.1016/j.tetlet.2009.09.153

71. Zheng, X.; Qian, Y.-B. and Wang, Y. M. Eur. J. Org. Chem. 2010, 515.

http://dx.doi.org/10.1002/ejoc.200901088

72. Marianacci, O.; Micheletti, G.; Bernardi, L.; Fini, F.; Fochi, M.; Pettersen, D.; Sgarzani, V. and Ricci, A. Chem. Eur. J. 2007, 13, 8338.

http://dx.doi.org/10.1002/chem.200700908

PMid:17705329

73. Sukumari, S.; Azath, I. A.; Pitchumani, K. Synlett 2012, 23, 2328.

http://dx.doi.org/10.1055/s-0032-1317156

\section{Authors' Biographies}

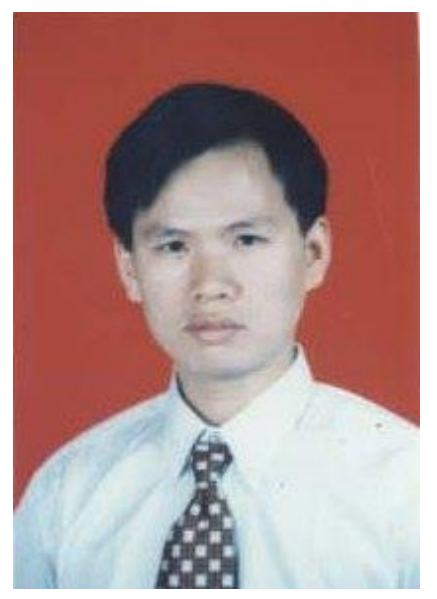

Xiao-hua Cai was born in 1966. He graduated at Shaoyang Technology University, China, in 1988. He received his M.S. in chemistry from Xi'an Modern Chemistry Research Institute in 1999, and his Ph.D. in sciences from Graduate School of theChinese Academy of Sciences in 2005. he became a professor at College of Chemistry and environmental Science, Guizhou Minzu University in 2006, His research interests are in the fields of organic reactions, drug molecular design, and bioactivity of natural products. 


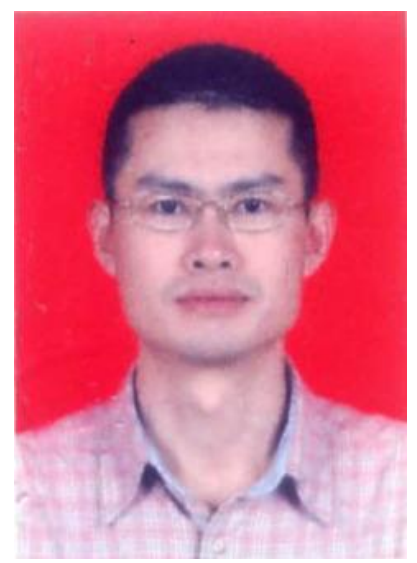

Bing Xie was born in 1963. He is a senior professor of Guizhou Minzu University, Guiyang. He graduated at southwest normal university, China, in 1985. He received his M.S. in chemistry from Guizhou university 2006. His research interests is focused on the synthesis of heterocyclic compounds which may have prospective biological and pharmaceutical activities. 